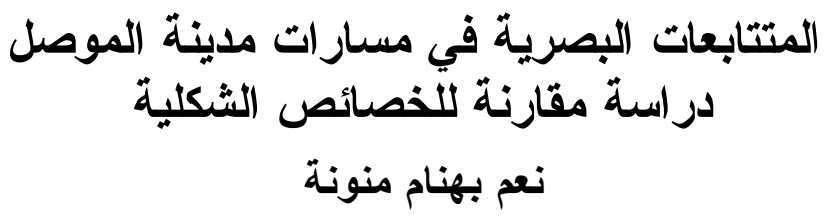

مدرس مساعد - قسم الهنسة المعمارية/جامعة الموصل

الخلاصة

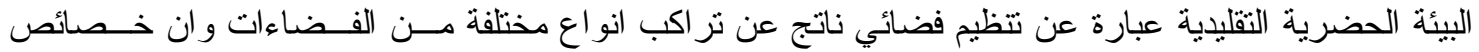

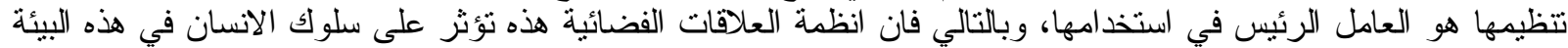

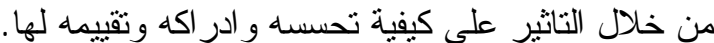

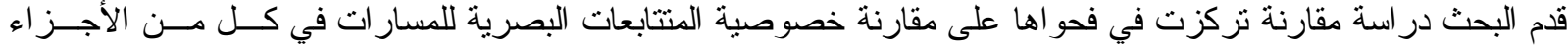

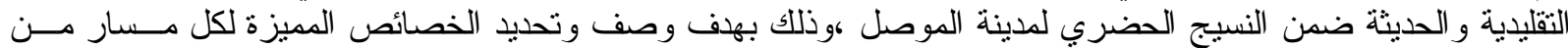

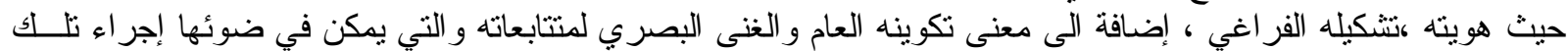

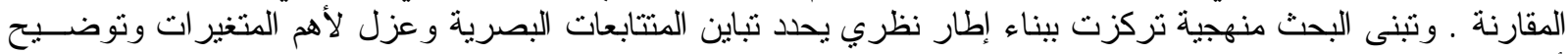

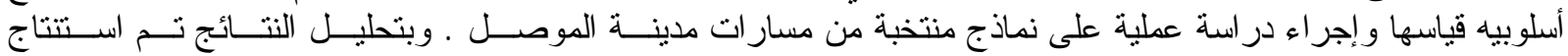

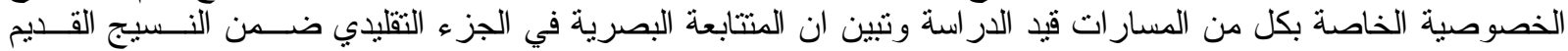

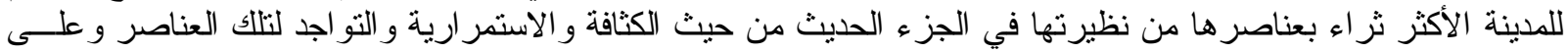
طول المسار.

\title{
Visual Sequences in Mosul City Paths A comparative Study for formal characteristics
}

\author{
Niam .Behnam Manona \\ Department of Architecture- University of Mosul
}

\begin{abstract}
The urban environment is a spatial organization synthesized from different types of spaces, it's characteristics are the key factor of it's use because spatial relationship usually affect human behavior within the environment by affecting the ways he perceives, cognized and evaluates it.

This research is a comparative study concerning the differences of the visual composition of the urban paths of tradional and modern parts in the city of Mosul. It's objective is to describe and define the characteristics of those paths in terms of their identity, spatial formulation, the meaning of their composition and the richness of their visual sequence.

By adopting a clear methodology and simplified objective measures, the research concluded the visual richness of the patgs under, study, in addition to suggesting the possibility of using the measures used in it to evaluate future designs of urban paths.
\end{abstract}

Key word : Visual Sequences, Urban Path 


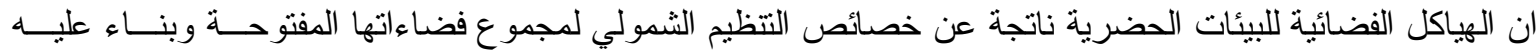

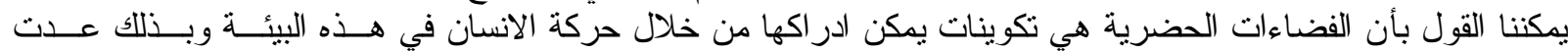

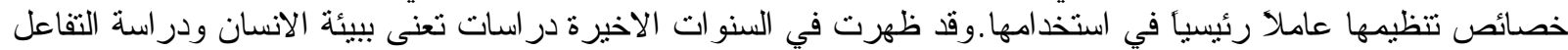

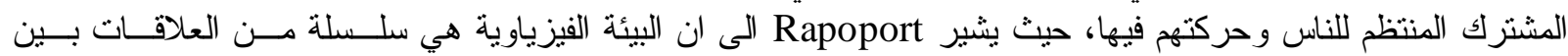

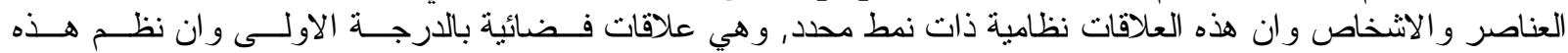

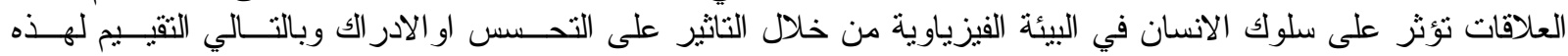

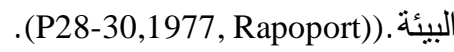
ان هذا البحث هو محاولة لاستثمار التطور ات المات المعرفية في هذا المجال من اجل توفير اطار معرفي يمكن الاستفادة منه

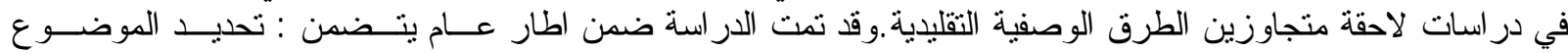

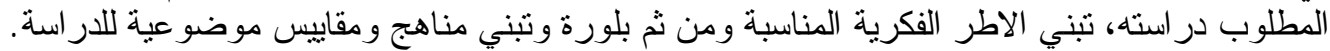

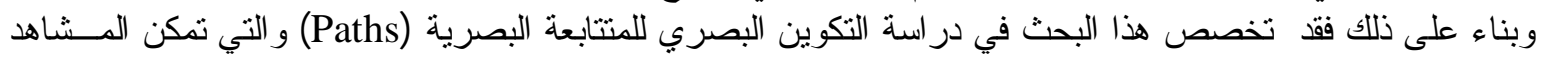

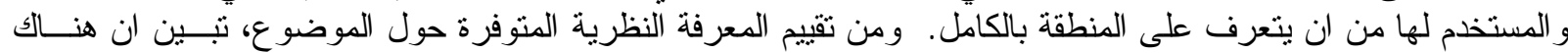

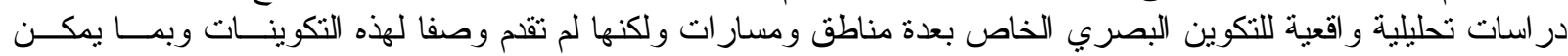

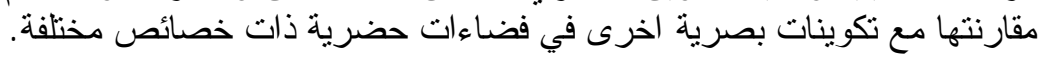

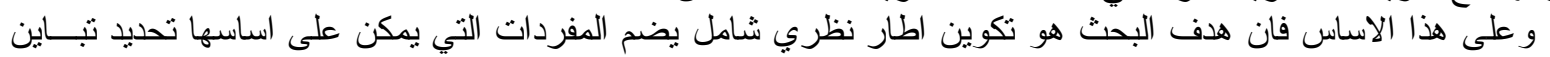

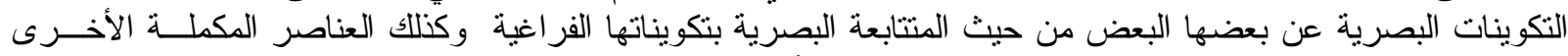

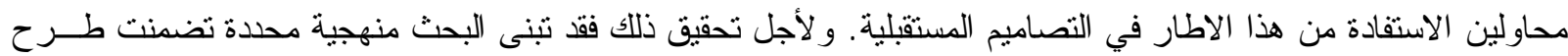

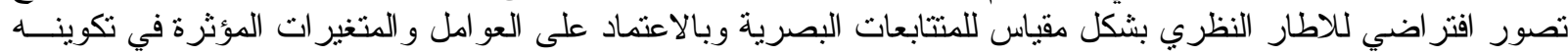

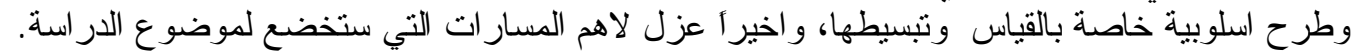

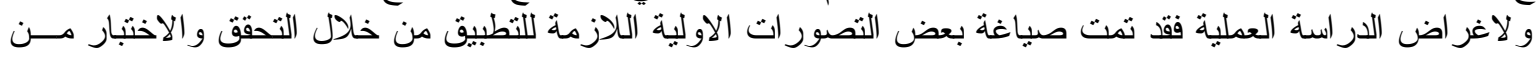

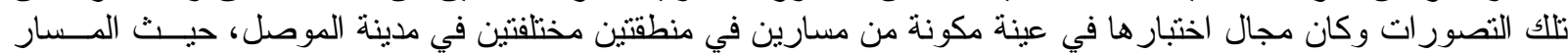
الاول في الاحياء الحديثة و المسار الثاني في الاحياء القياء القديمة.

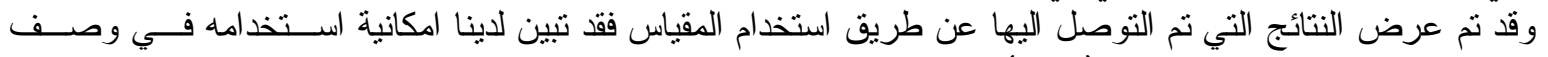

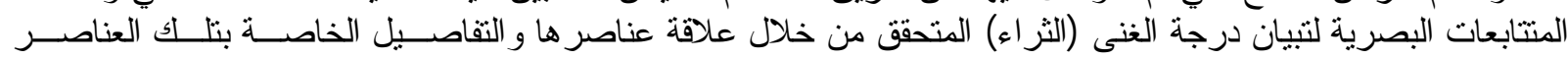
بعضها بالبعض الاخر مانة

\section{1 -ماهية التكوين البصري للمسارات الرئيسية}

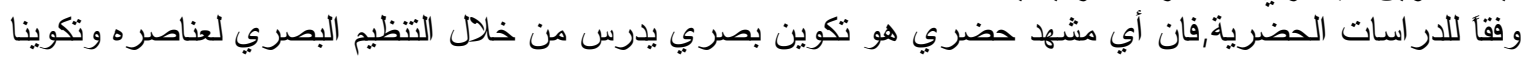

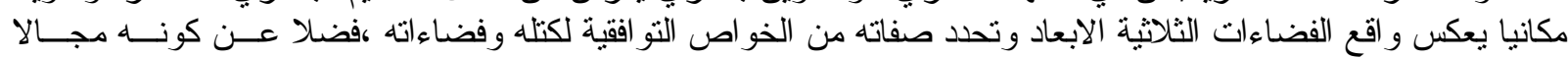

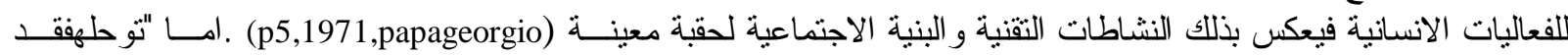

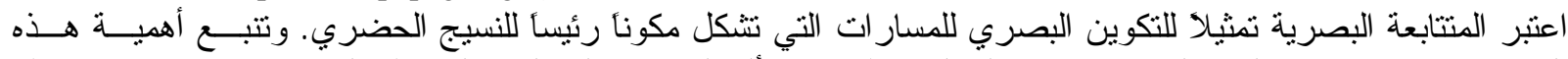

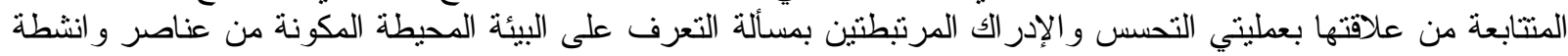

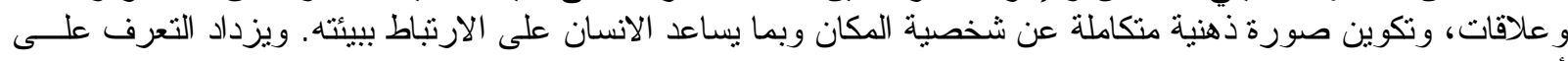

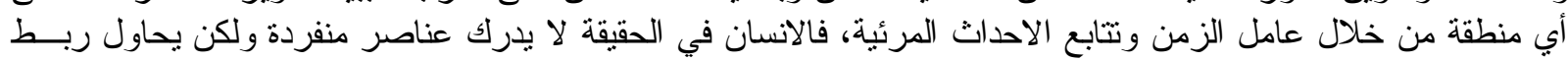

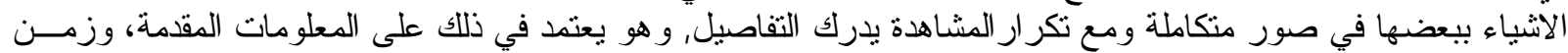

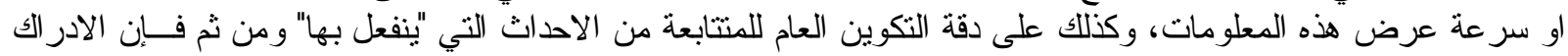

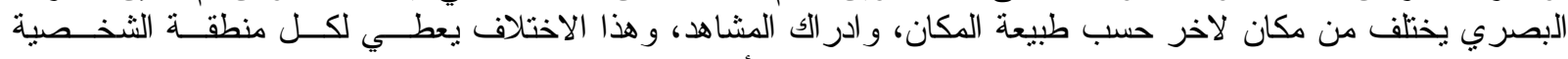

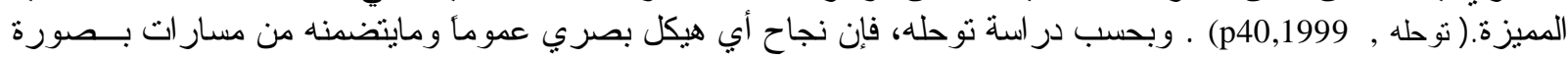

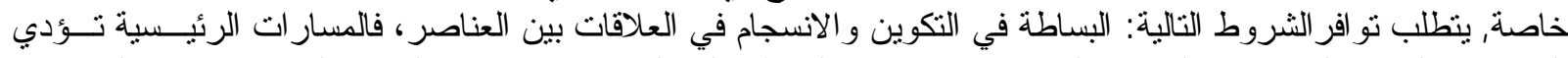

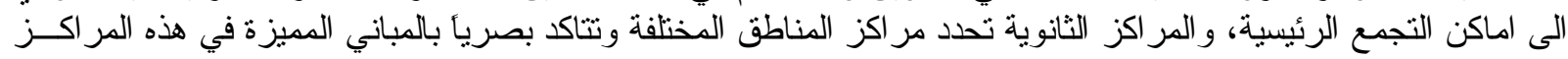

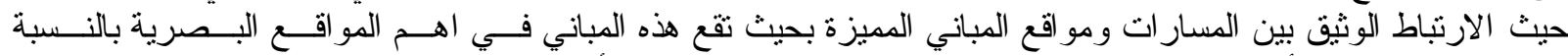

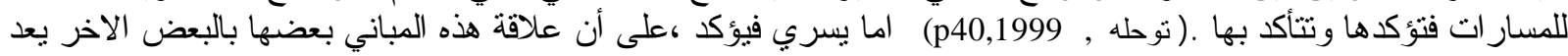

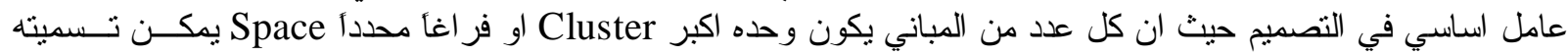




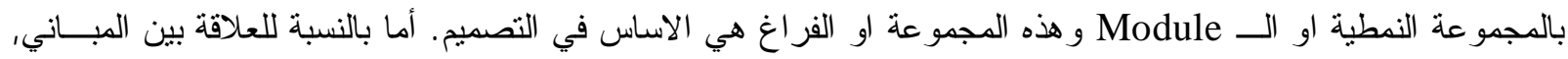

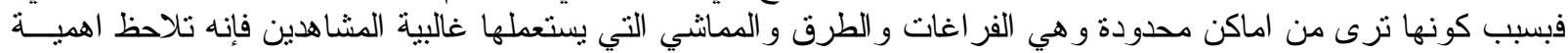

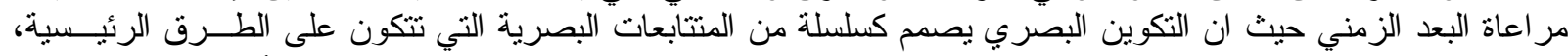

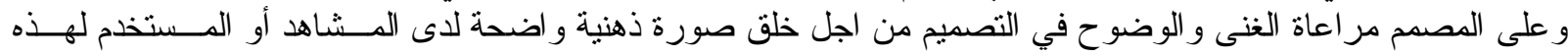

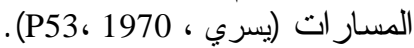

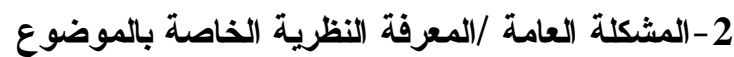

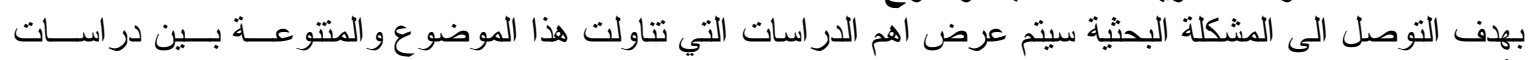

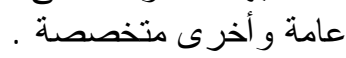

\section{| 1-2 2}

لغرض بيان أهية الموضوع الفرية سيتم التطرق الى بعض الطروحات المرتبطة به تتاول Rapoport في دراسته الموسومة

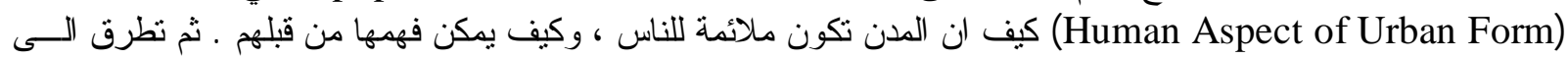

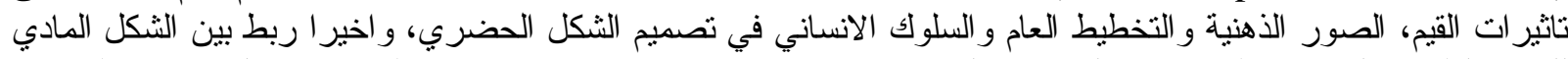

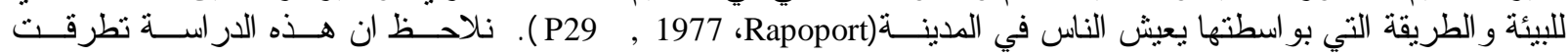

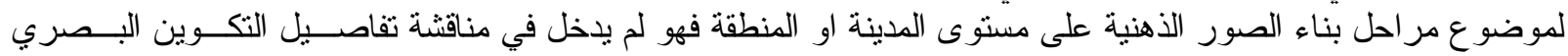

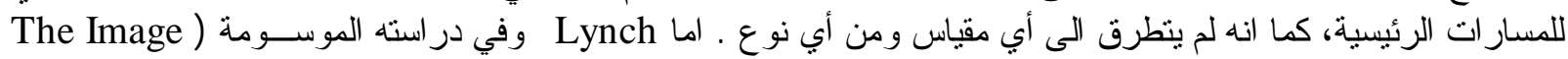

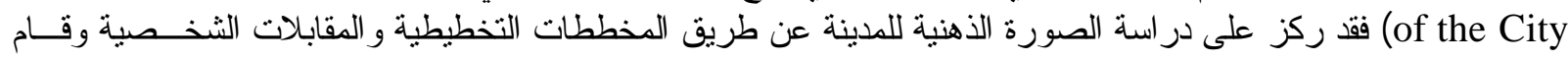

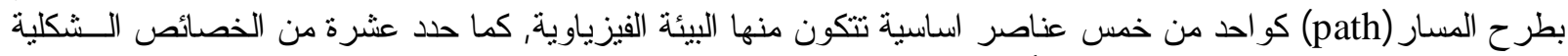

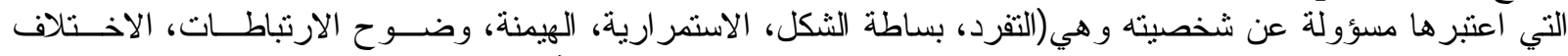

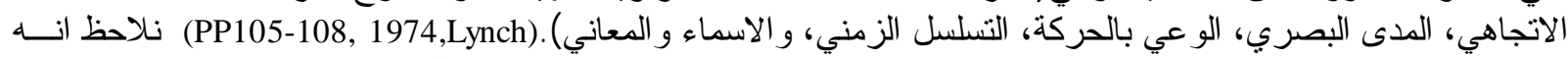

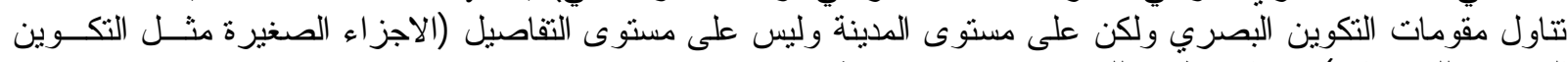

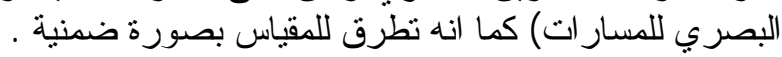

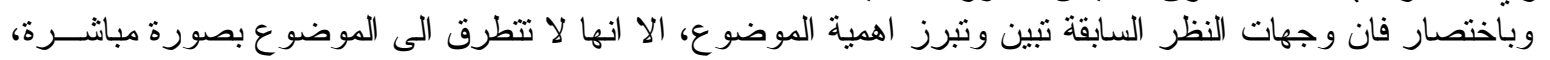

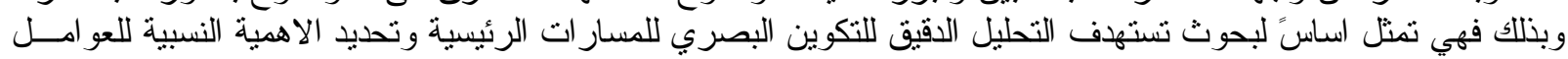
الاخلة في تكوينه.

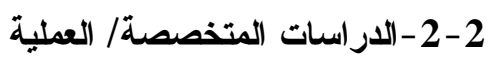

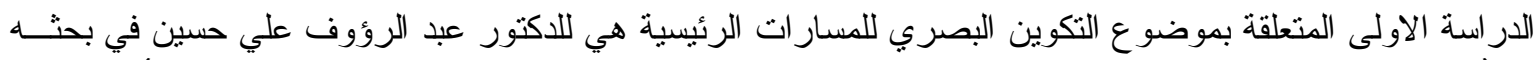

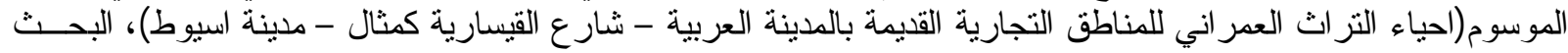

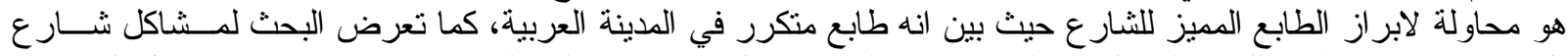

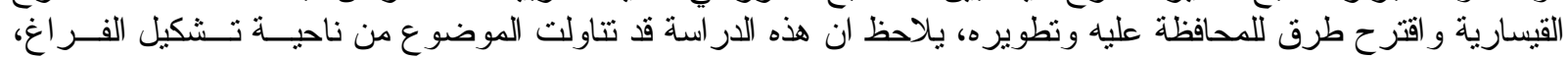

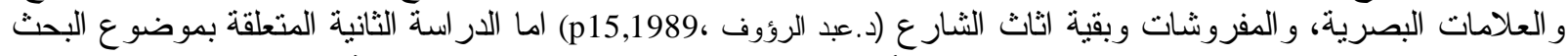

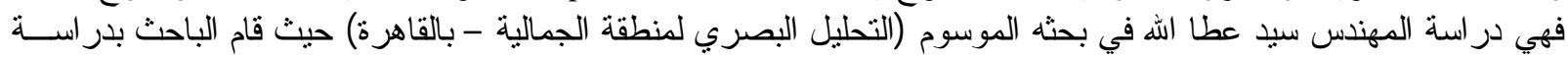

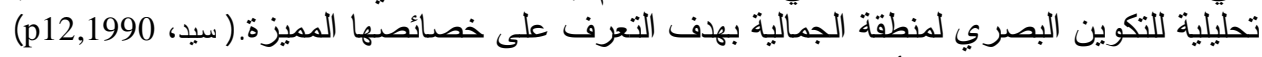

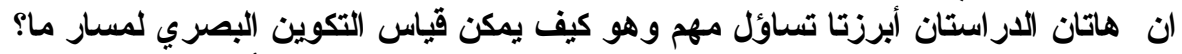

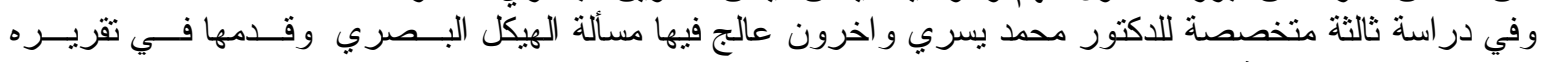

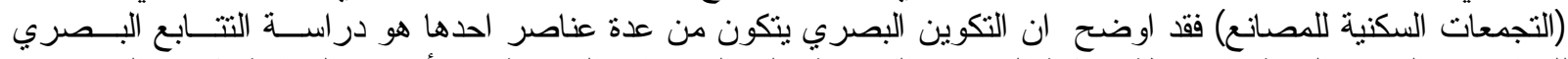

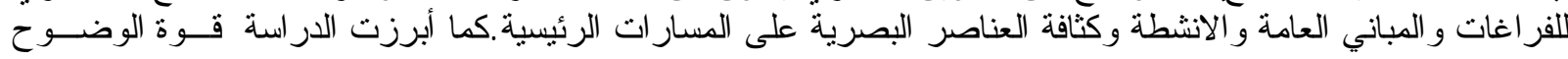

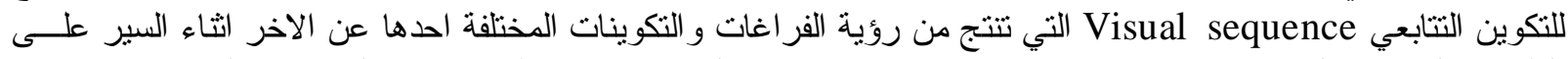

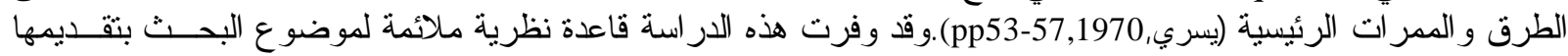

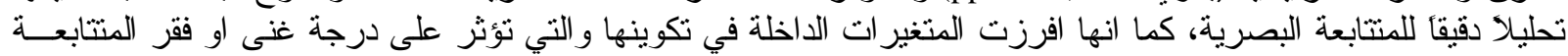

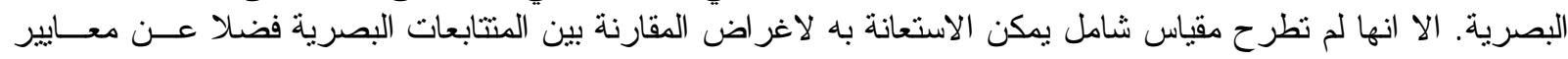

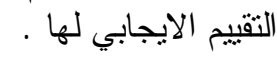




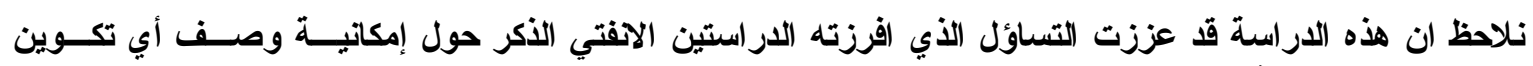

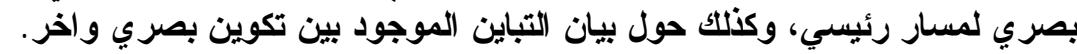

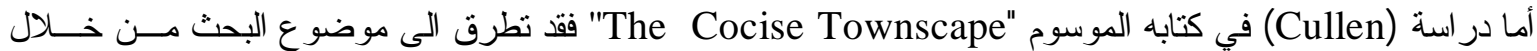

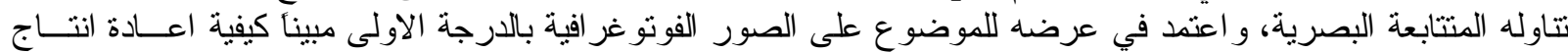

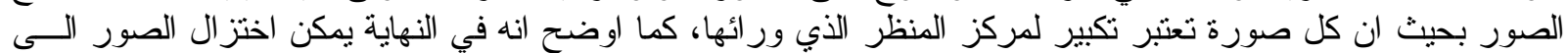

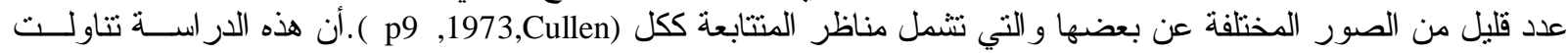

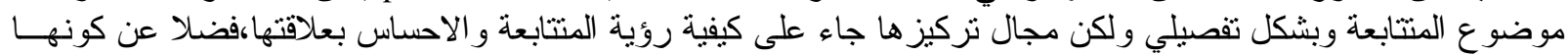

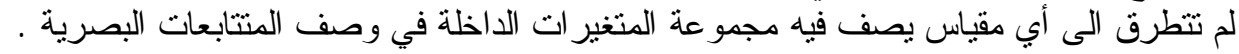
ومن الدر اسات المتخصصة في موضوع البحث هي در اسة (Mc Cluskey) في كتابه الموسوم

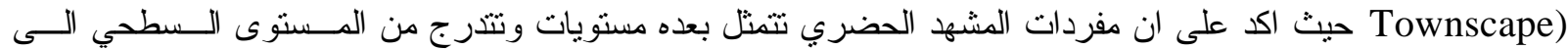

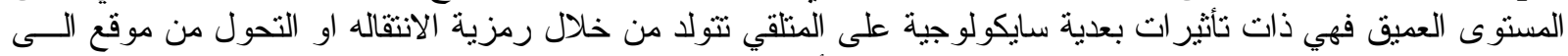

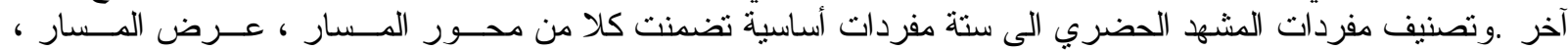

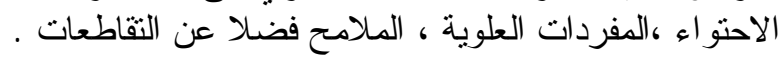

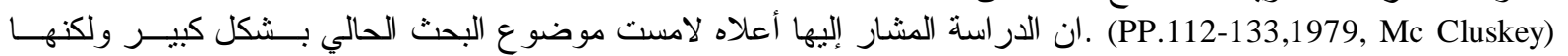

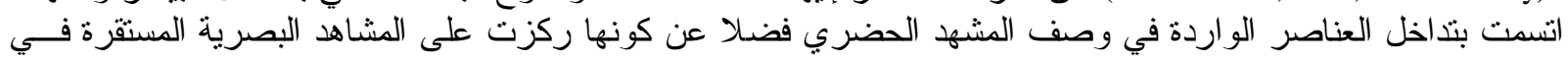

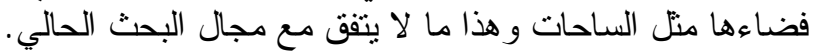

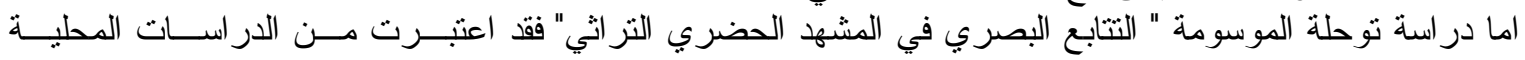

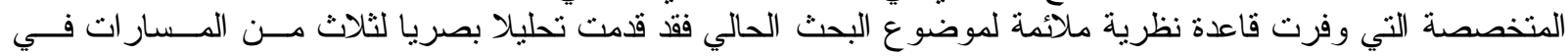

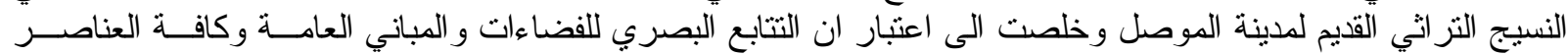

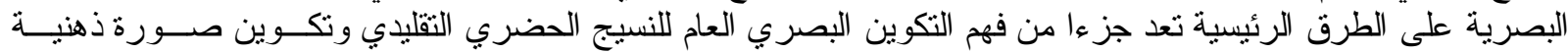

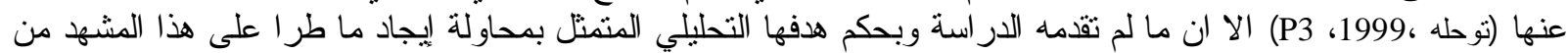

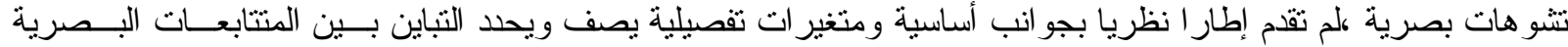

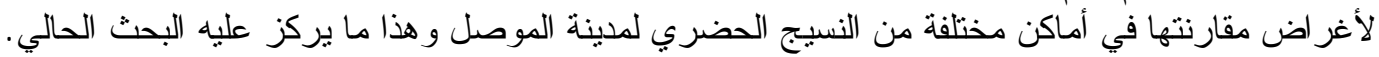

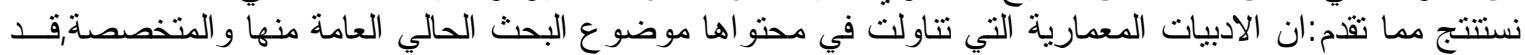

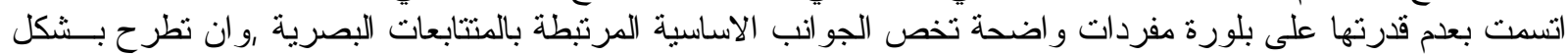

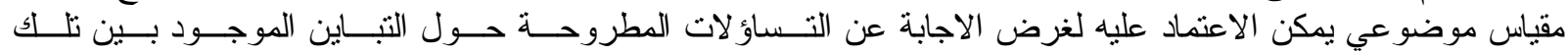

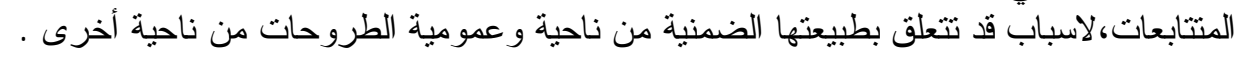

3 - مشكلة البحث و هدفه ومنهجه:

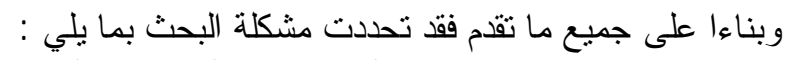

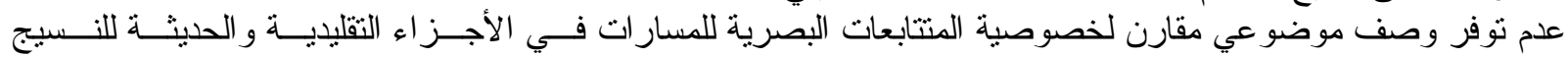

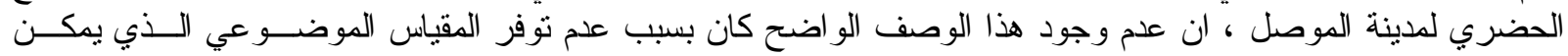

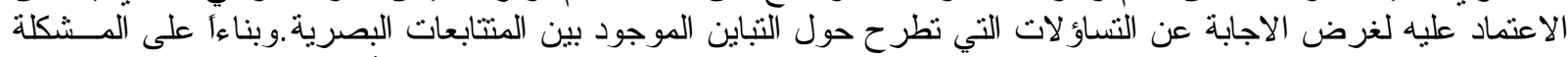

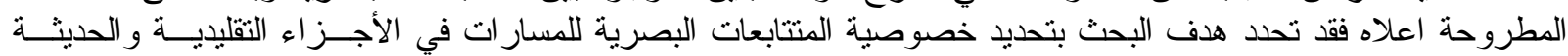

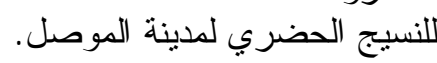

ولغرض تحقيق هدف البحث اعلاه فقد تنبى منهجأ يتحقق بالمر احل التالية :

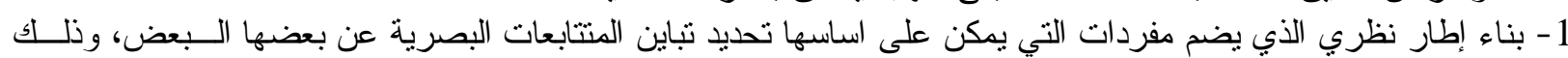

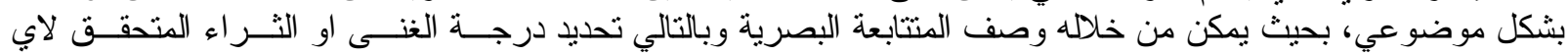

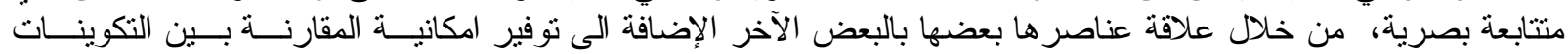
البصرية للمسار ات.

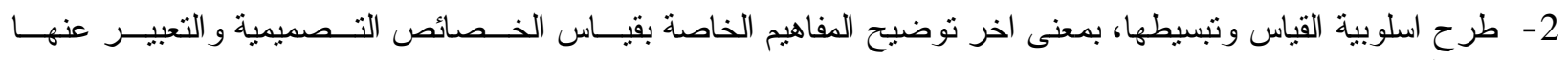
ووصفها.

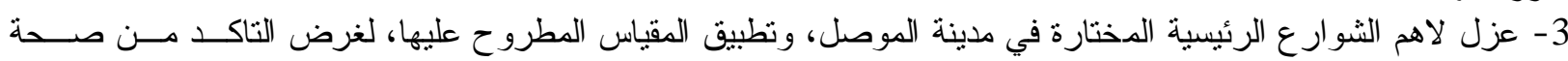
الفرضية الفرضية البحثية. 
4 - 4 - تحليل نتائج القياس لتحديد خصوصية للمنتابعة البصرية.

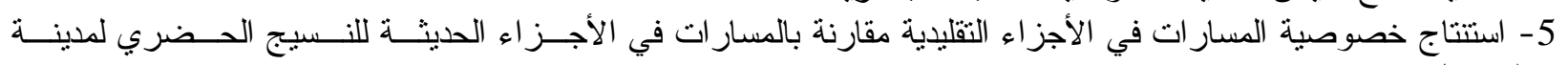
الموصل.

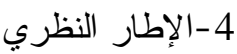
لغرض بلورة الاطار النظري سيتم عرض لإر لإنم الدر اسات السابقة ذات الصلة المباشرة بموضوع البحث وذلك لغــرض فرز المتغير ات التي سيتم الاعتماد عليها في تشكيل المقياس.

\section{1-4 - 1ستكثاف الأطر الكامنة في الطروحات المعمارية}

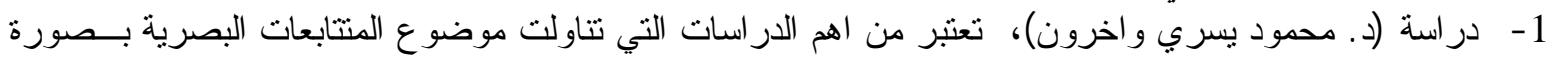

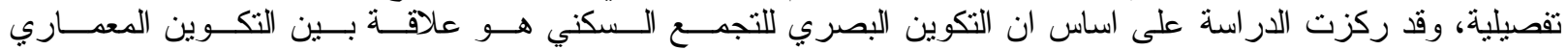

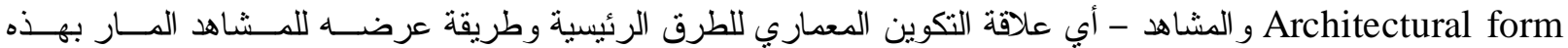

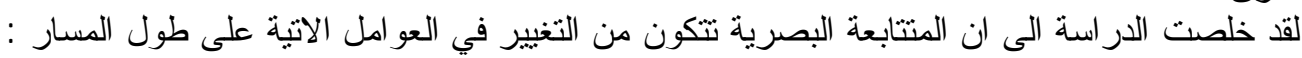

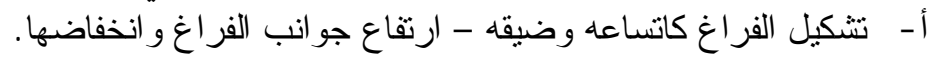

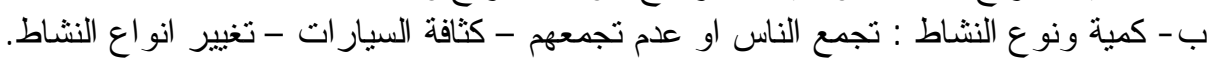

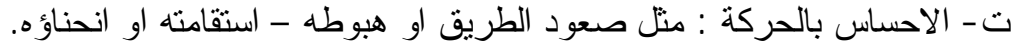

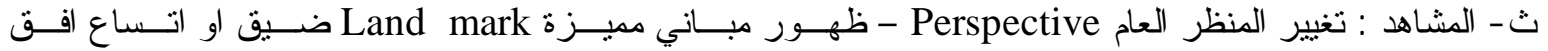

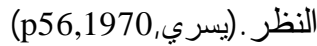
تعكس الطروحات انفة الذكر بعض من جوانب ترتبط بالمتتابعات البصرية شملت كلا من حافات الفضاء،نوع النـشاطات

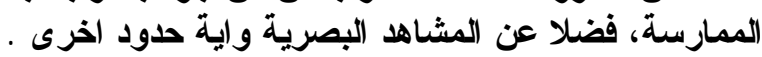

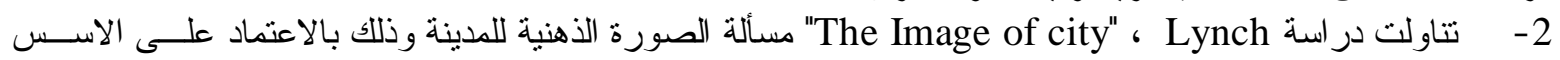

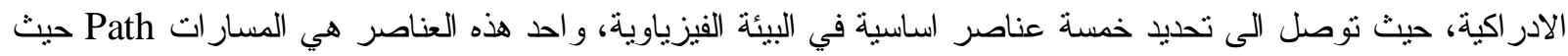

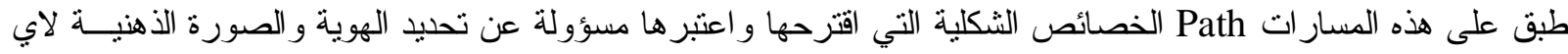

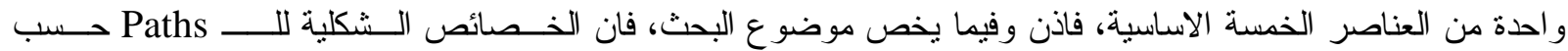

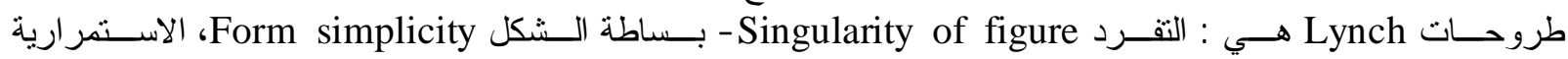
Dontinuity Time Vifferentiation scope

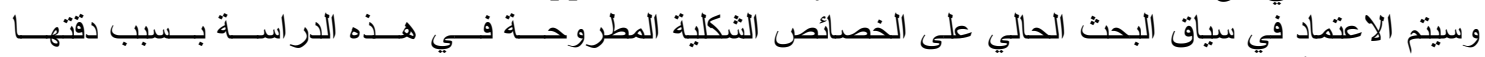

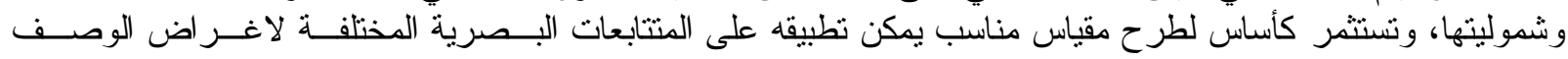

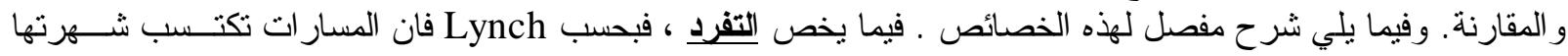

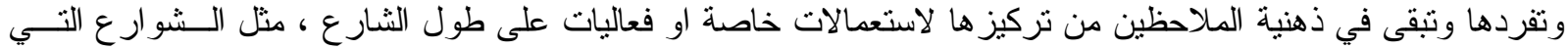

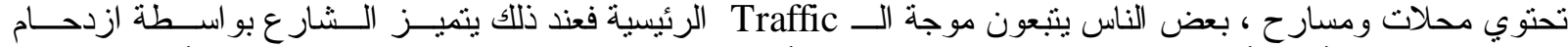

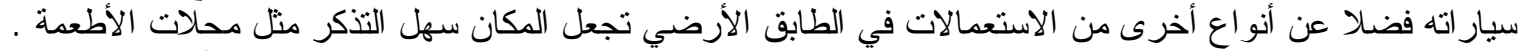

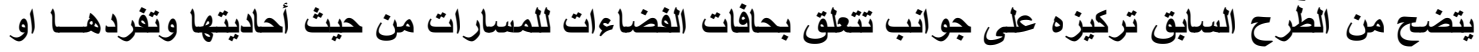

بحسب استعمالاتها هن .

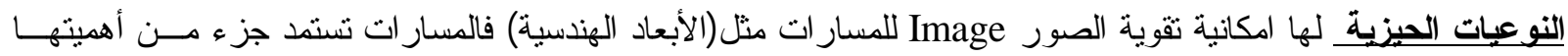

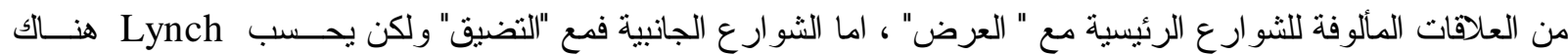

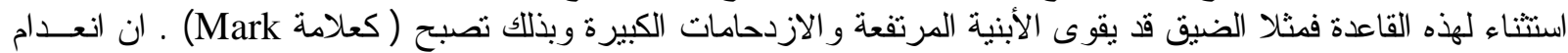

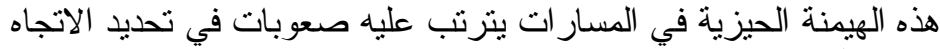
شخصية الواجهات الخاصة تلعب دورا مهما في تحديد هوية الممر وان وجود الاتشجار بشكل يقوي الصورة الذهنية للمسار بصورة فعالة . 


\section{$\begin{array}{llll}\text { Al-Rafidain Engineering } & \text { Vol.17 } & \text { No.5 } & \text { October } 2009\end{array}$}

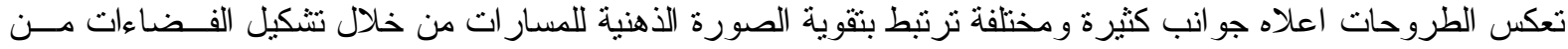

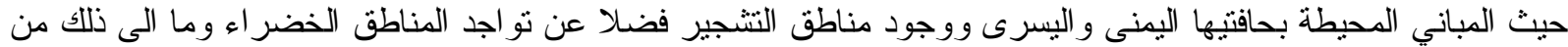

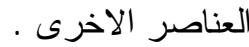

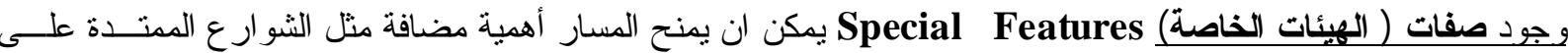

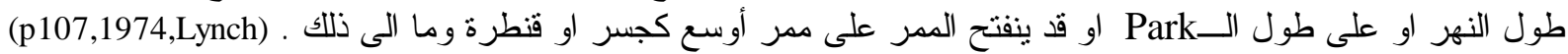

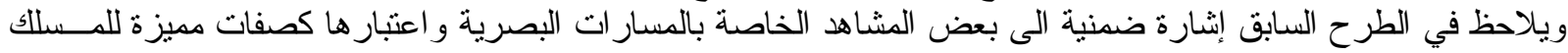

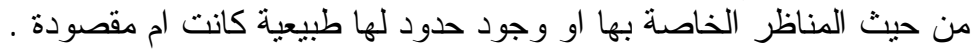

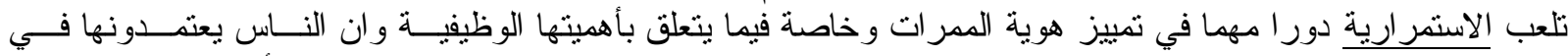

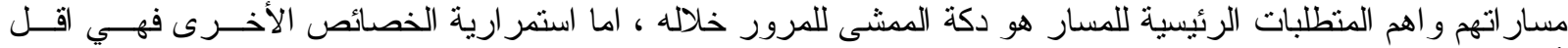

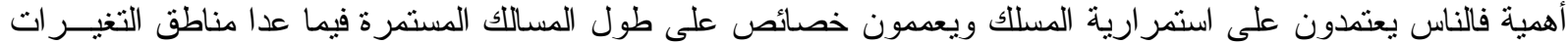

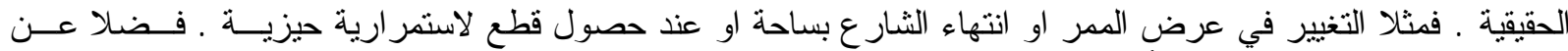

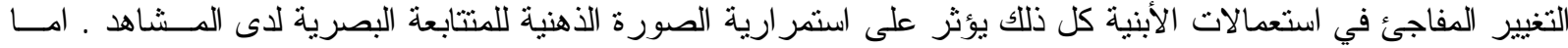

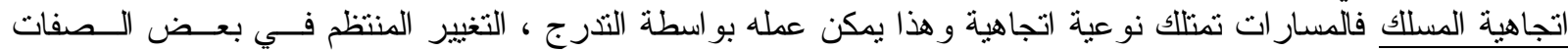

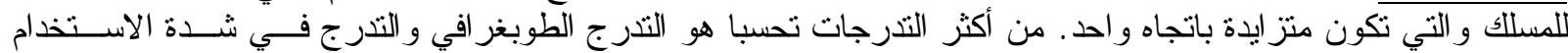

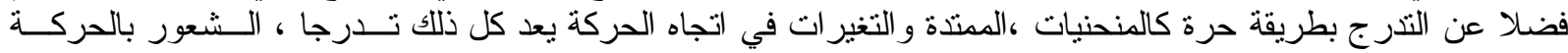
الجسمانية ، الاستذارة بسبب انغلاق الجدران يدفع الإحساس للانحناء ـ (p107,1974,Lunch)

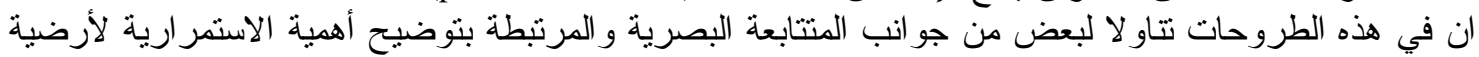

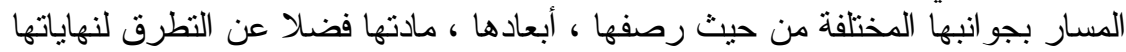

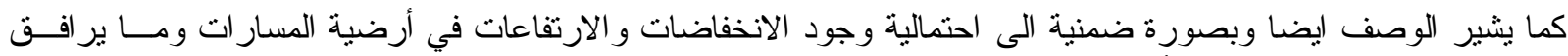

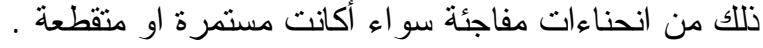

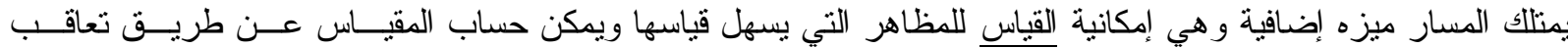

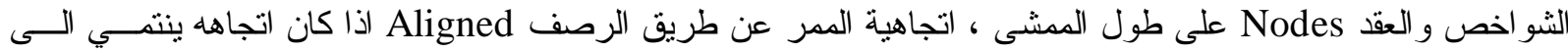

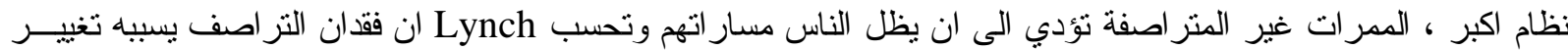

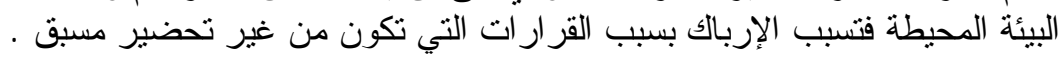

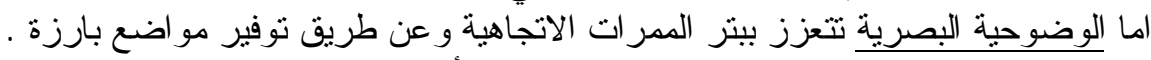

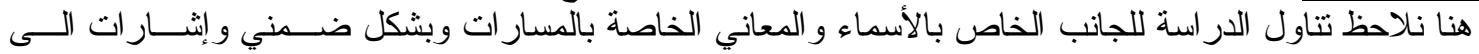

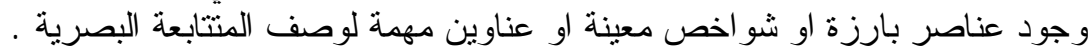

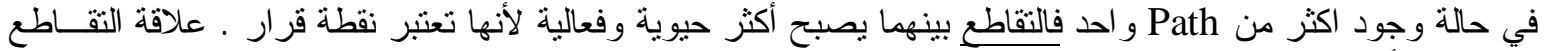

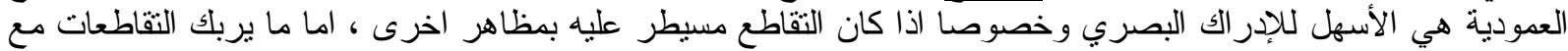

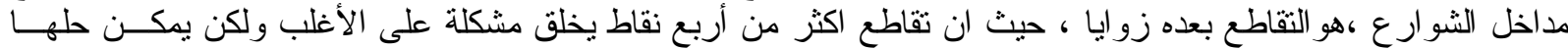

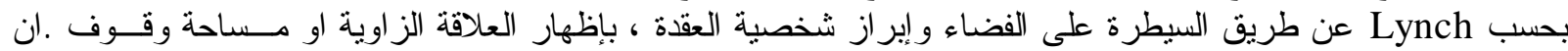

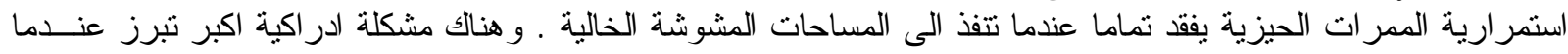

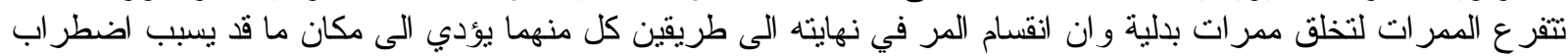
عنيف في الصورة الذهنية ـ (p108,1974,Lunch)

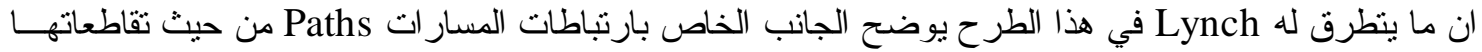

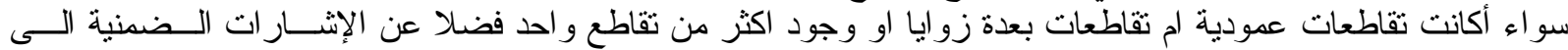

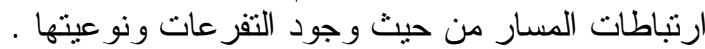

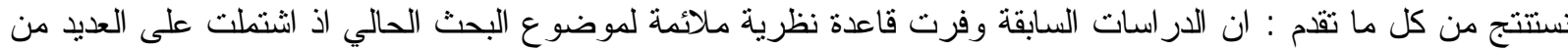

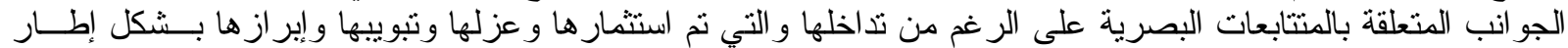

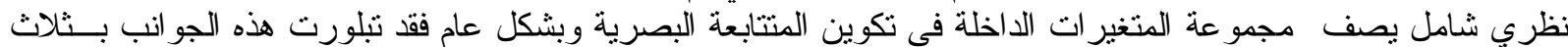

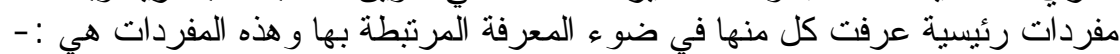

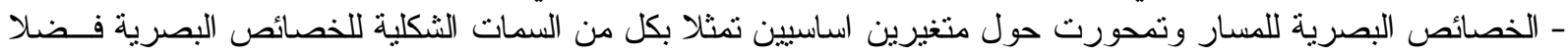

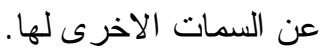


منونة : المتتابعات البصرية في مسارات مدينة الموصل دراسة مقارنة للخصائص الثكلية

- الخصائص التصميمة (الثكلية) للمسار وتمحورت حول ست متغير ات اساسية تمثلت بكل من تثكيل الفضاء ، تكوين

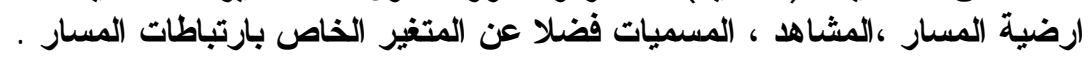

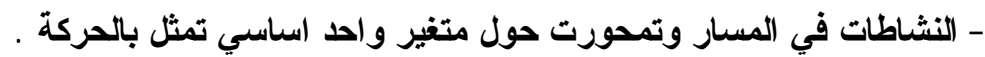
يتم نوضيح ما امكن استخلاصه من الجو انب الخاصة بالاطار النظري و القيم الممكنة لمتغير اته في الثكل رقم (1). الثكل (1) القيم الممكنة للمفردة الاولى (الخصائص البصرية للمسار).

\begin{tabular}{|c|c|c|c|c|c|}
\hline عدم وجود شكل متميز & وجود شكل متميز & وجود شكل & \multirow{2}{*}{ من ناحية } & \multirow{10}{*}{ 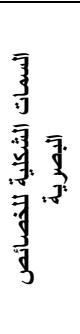 } & \multirow{14}{*}{$\begin{array}{l}\bar{y} \\
\overline{3} \\
\overline{3} \\
\overline{3} \\
3 \\
3 \\
3 \\
3\end{array}$} \\
\hline متقطع & مستمر & استمر ارية الشكل & & & \\
\hline عدم وجود التضاد & وجود تضاد مميز & وجود التضاد & \multirow{2}{*}{ من ناحية } & & \\
\hline متقطع & مستمر & استمر ارية التضاد & & & \\
\hline عدم وجود التكرار & وجود التكرار المحسوس & وجود التكرار & \multirow{2}{*}{ من ناحية } & & \\
\hline متقطع & مستمر & استمر ارية التكرار & & & \\
\hline عدم وجود الملمس & وجود الملمس المتميز & وجود ملمس & \multirow{2}{*}{ من ناحية } & & \\
\hline متقطع & مستمر & استمر ارية الملمس & & & \\
\hline عدم وجود اللون & وجود لون متميز & وجود اللون & \multirow{2}{*}{ من نـاحية اللون } & & \\
\hline متقطع & مستمر & استمر ارية اللون & & & \\
\hline عدم وجود الروائح & وجود الروائح المتميزة & وجود الروائح & من ناحية & \multirow{4}{*}{$\frac{3}{3} \cdot \overline{1}$} & \\
\hline متقطع & مستمر & استمر ارية الروائحتح & الروائح & & \\
\hline عدم وجود الأصوات & وجود الأصوات المتميزة & وجود الاصوات & \multirow{2}{*}{ الصن نـاحية } & & \\
\hline متقطع & مستمر & استمرارية الاصوات & & & \\
\hline
\end{tabular}

تابع الثكل (1) (القيم الممكنة للمفردة الثانية ((الخصائص التصميمية (الثكلية) للمسار))

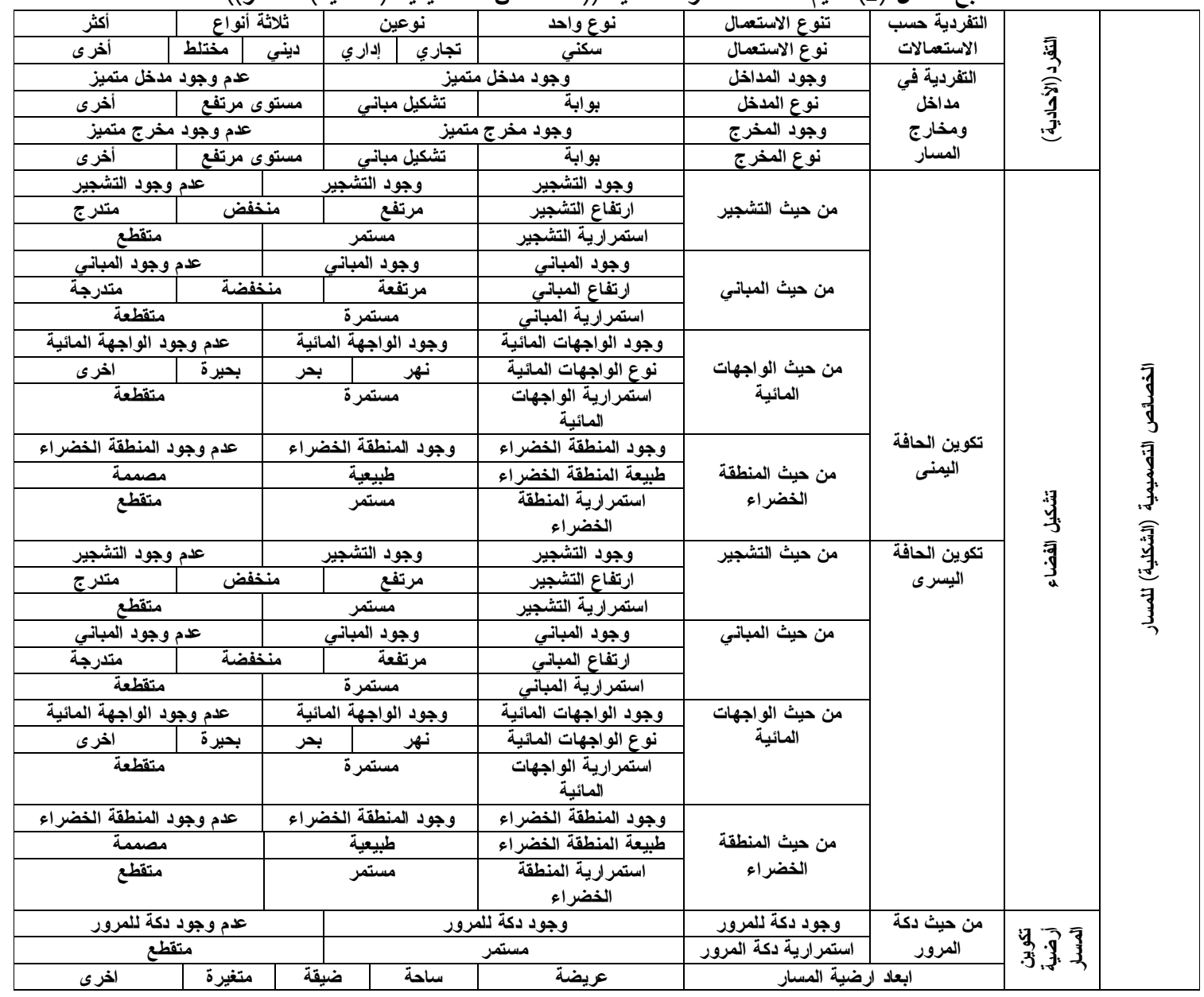


Al-Rafidain Engineering

Vol.17 No.5

October 2009

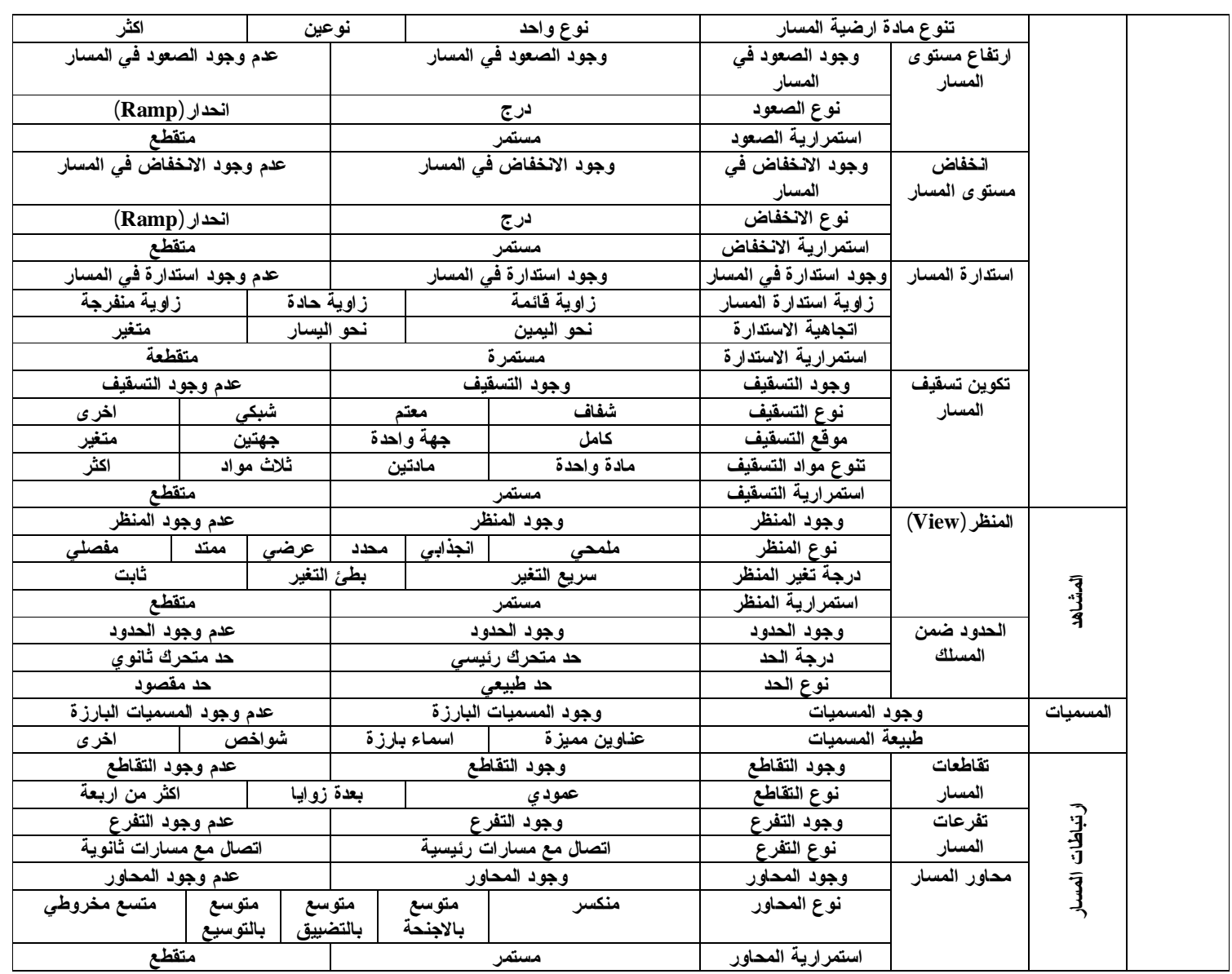

\begin{tabular}{|c|c|c|c|c|c|c|}
\hline \multicolumn{2}{|c|}{ عدم وجود الحركة } & \multicolumn{2}{|c|}{ وجود الحركة } & وجود الحركة & \multirow{6}{*}{ الحركة } & \multirow{6}{*}{ الممارسة في المسات } \\
\hline قليلة & & & كثيفة & كثافة الحركة & & \\
\hline \multicolumn{2}{|c|}{ متقطعة } & \multicolumn{2}{|c|}{ مستمرة } & استمر ارية الحركة & & \\
\hline اخزى & مختلط & سيارات & 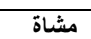 & نوع الحركة & & \\
\hline \multicolumn{2}{|c|}{ اتجاهين } & \multicolumn{2}{|c|}{ اتجاه واحد } & اتجاه الحركة للسيارات & & \\
\hline وقوف & متغيرة & بطيئة & سريعة & سرعة الحركة & & \\
\hline
\end{tabular}

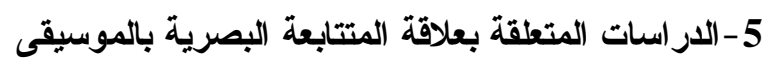

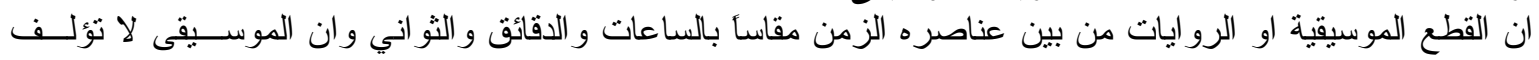

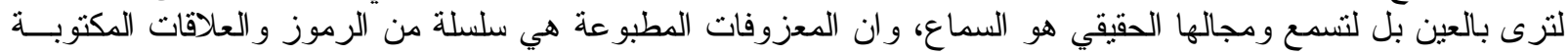

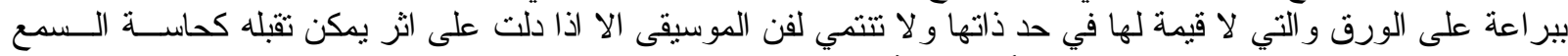

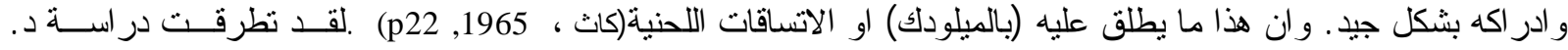

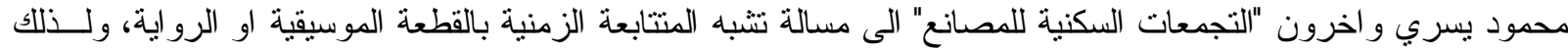

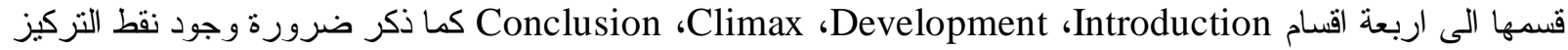
Accentuation

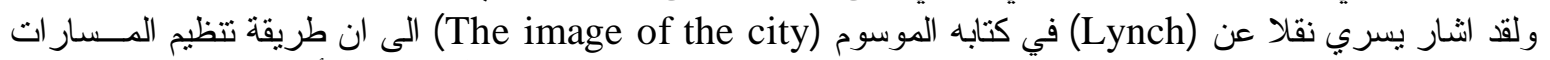

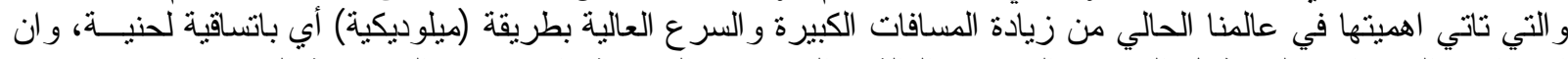
الاحداث و المميز ات على طول المسار و العلامات الدالة، و التشكيلات الفضائية، الاحاسيس الديناميكية المتغيرة بــين مـشهـ 


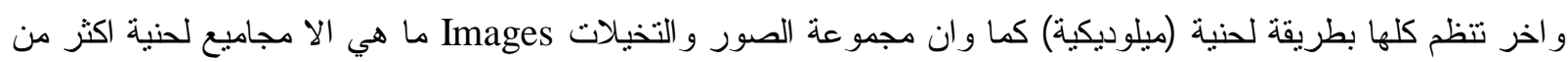

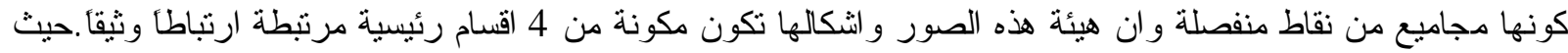

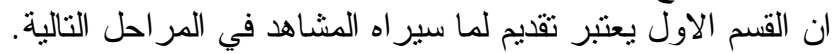

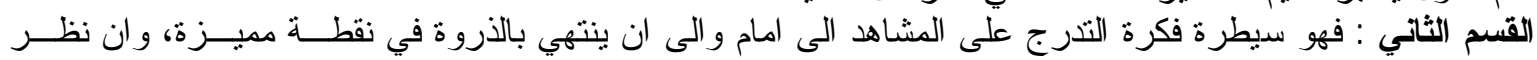

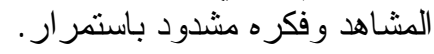
القسم الثالث : وهو القسم المركزي حيث يضدن النتهاء الصعود وفترة راحة وحرية وحرية في النظر يمينأ ويسار آ ويكون هذا

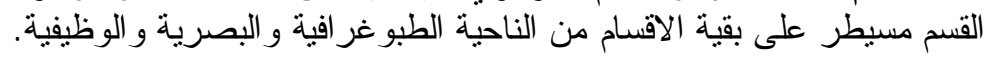

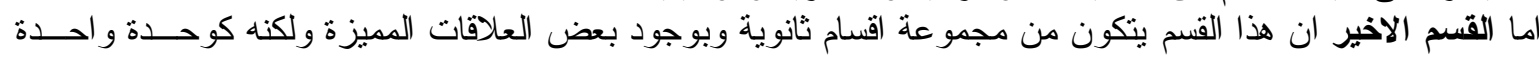

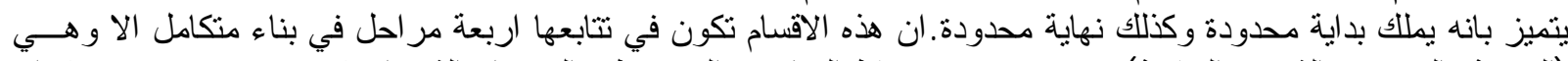

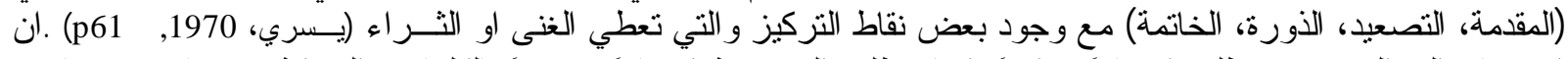

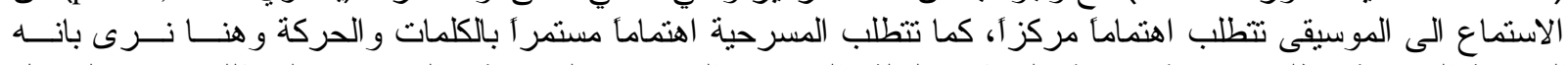

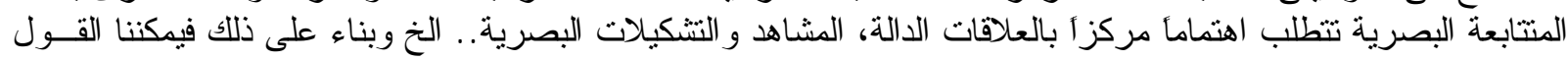

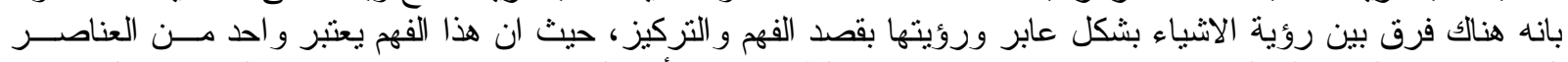

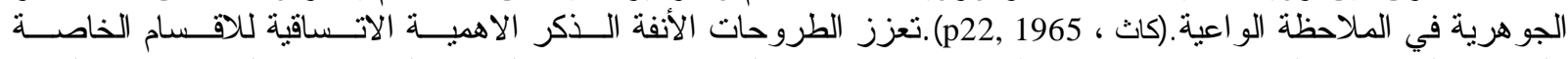

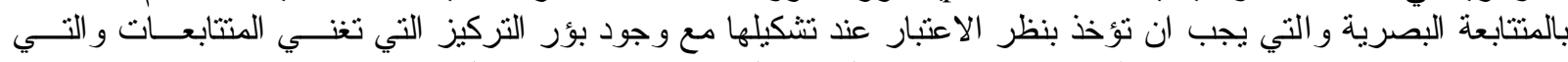

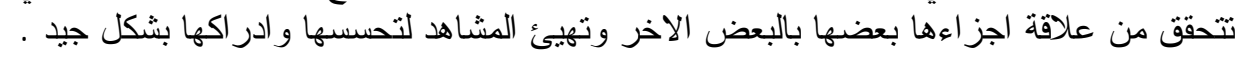

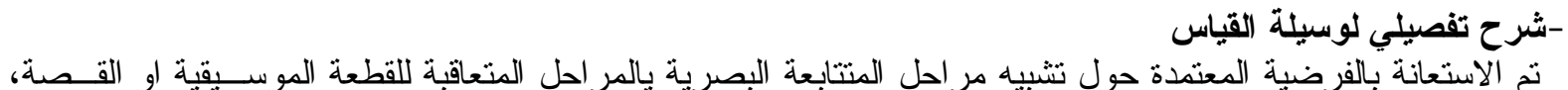

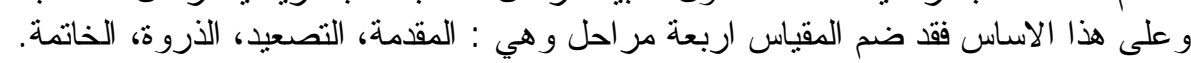

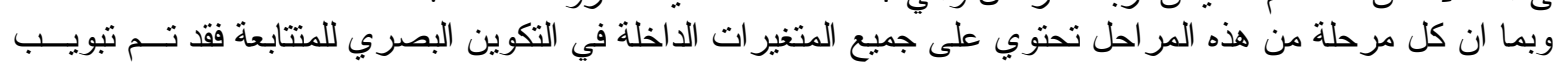

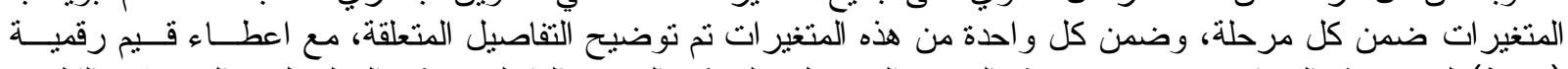

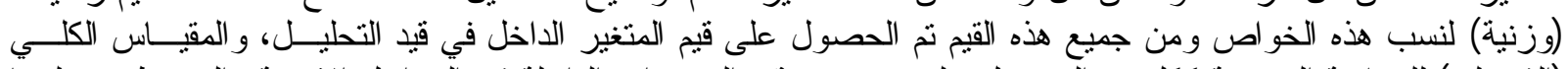

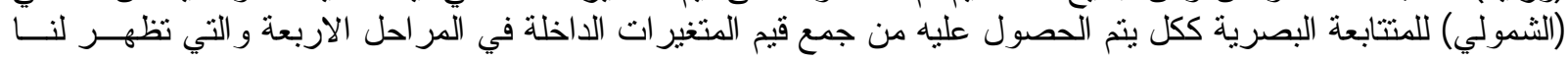

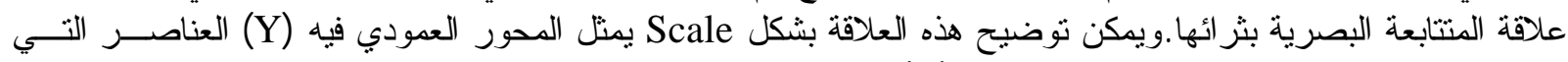

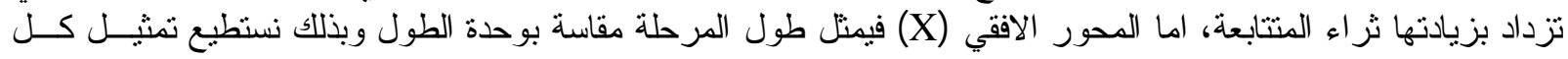

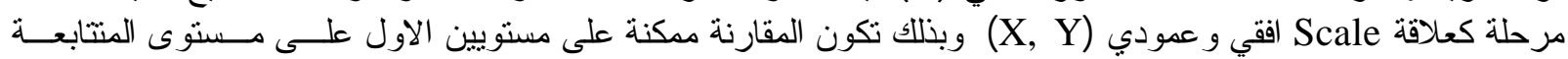

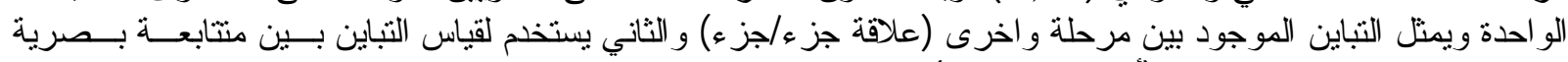

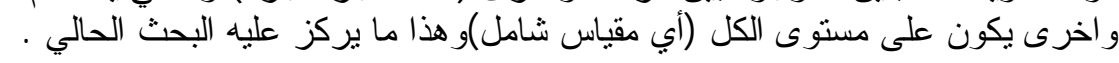

7 7 -التطبيق ئرن

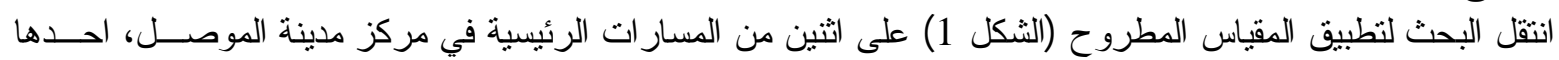

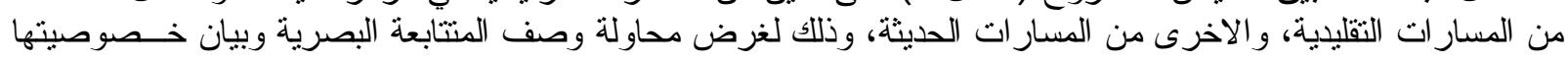

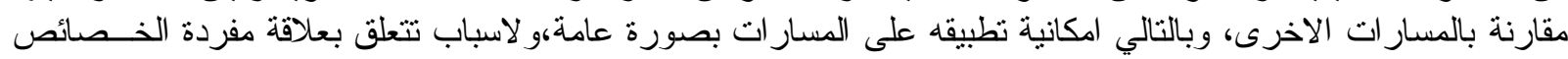

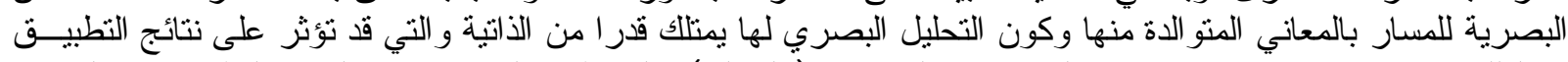

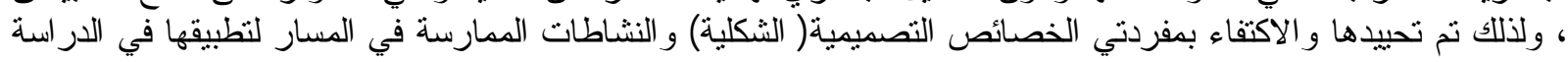

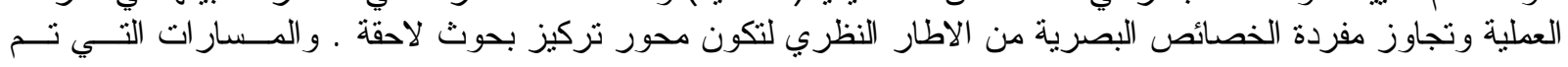

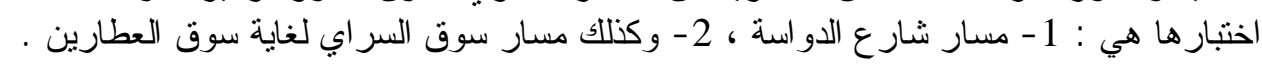

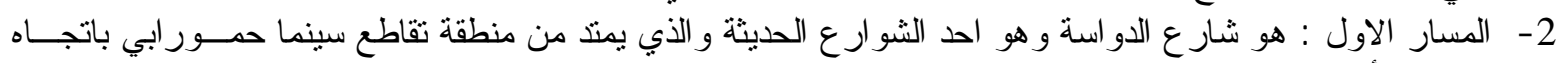

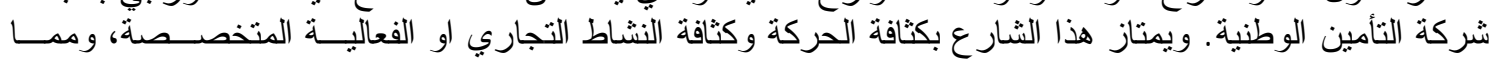

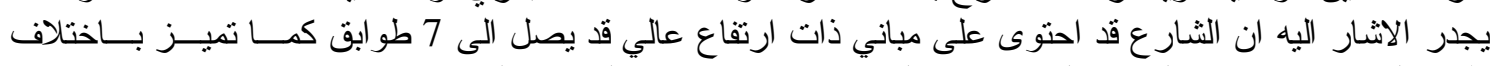

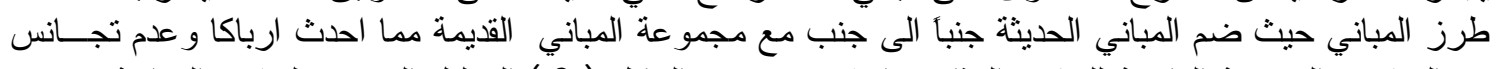
في العناصر البصرية المكونة للشارع المذكور اعلاه. ويوضح الثكل ( 2 التئي التحليل البصري لثار ع الدواسة. 


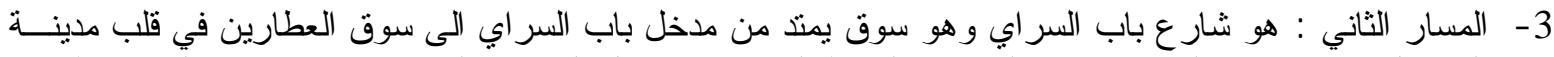

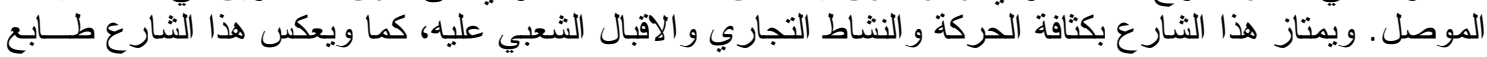

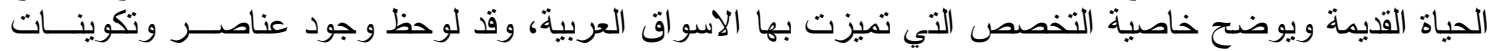

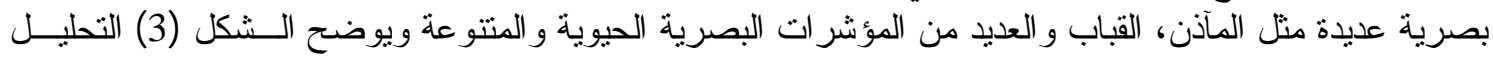

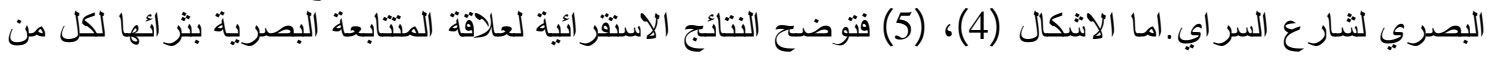

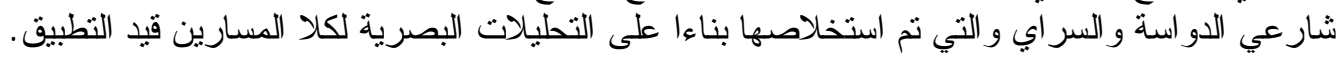

8 -مناقشة نتائج الدراسة العملية

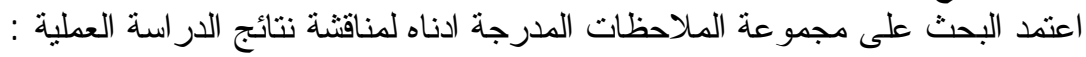
1 - ان تقسيم المتتابعة الى مر احل كان بالاعتماد على العقات العقد (Nodes) .

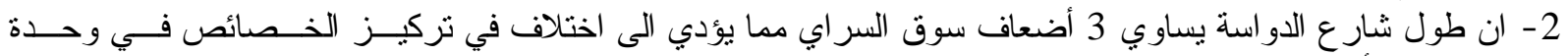

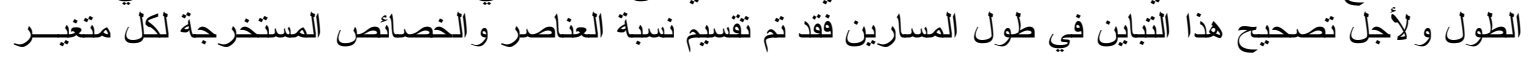

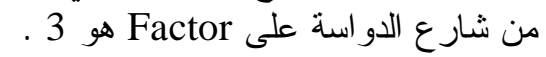

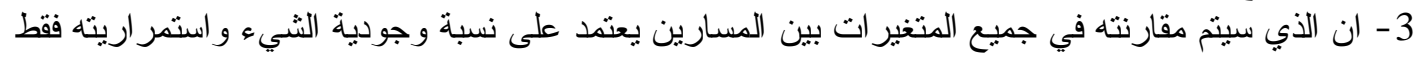

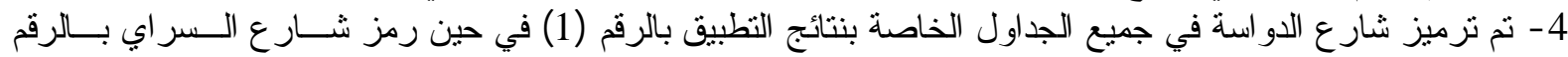
(2). وفيما يأتي استعر اض نتائج القياس وبحسب المتغير الخير ات الداخلة في تكوين المتتابعة فينة

1-8 - 1النتائج المتعلقة بالخصائص التصميمية (الشكلية للمسار):

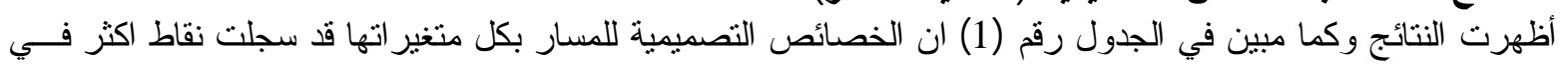

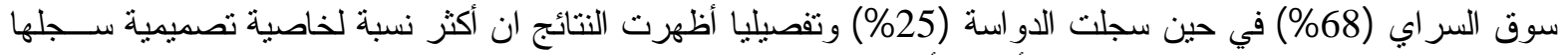

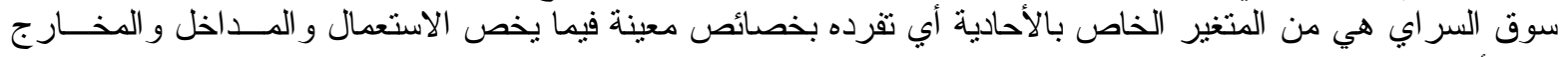

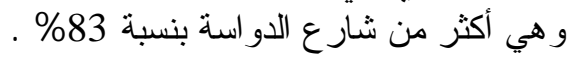

\begin{tabular}{|c|c|c|c|c|}
\hline & \multicolumn{3}{|c|}{ حافات الفضاء } & \\
\hline & $\% 68$ & & 55) $\% 71$ & \\
\hline (1)ارتباطات الكسار (2) & (1) الأسماء (2) & (1) الهشاهـ (2) & (1) تشكيل الفضاء(2) & (1) الأحادية \\
\hline \%75: \%88 & $\% 50:(33) \% 100$ & $\% 63: \% 63$ & $\% 75:(\% 25) \% 75$ & \% 100: (\%17) \% \\
\hline
\end{tabular}

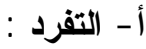

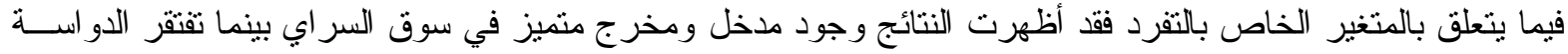

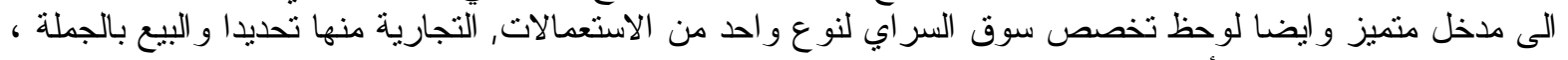

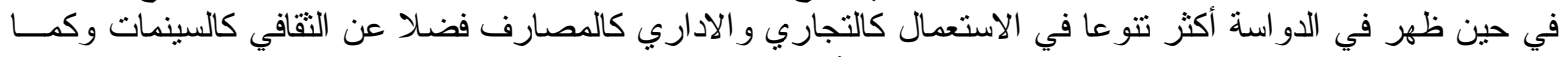

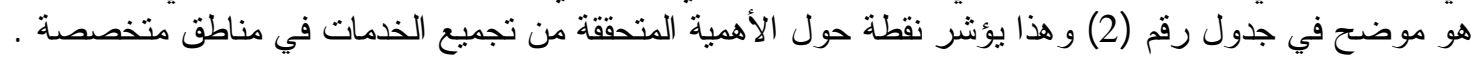



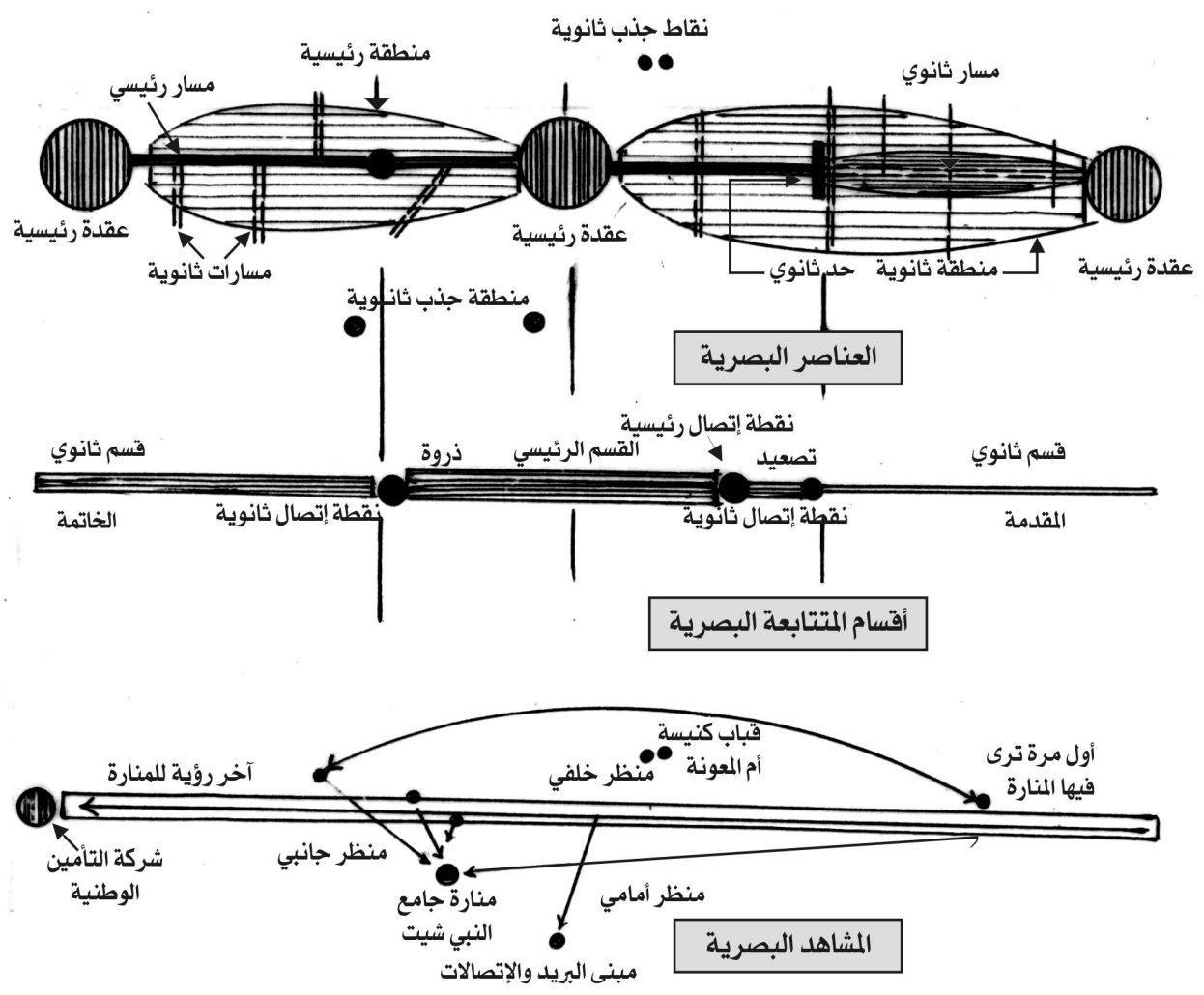

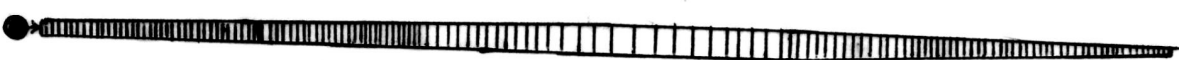

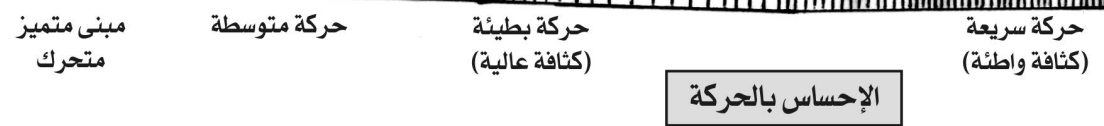
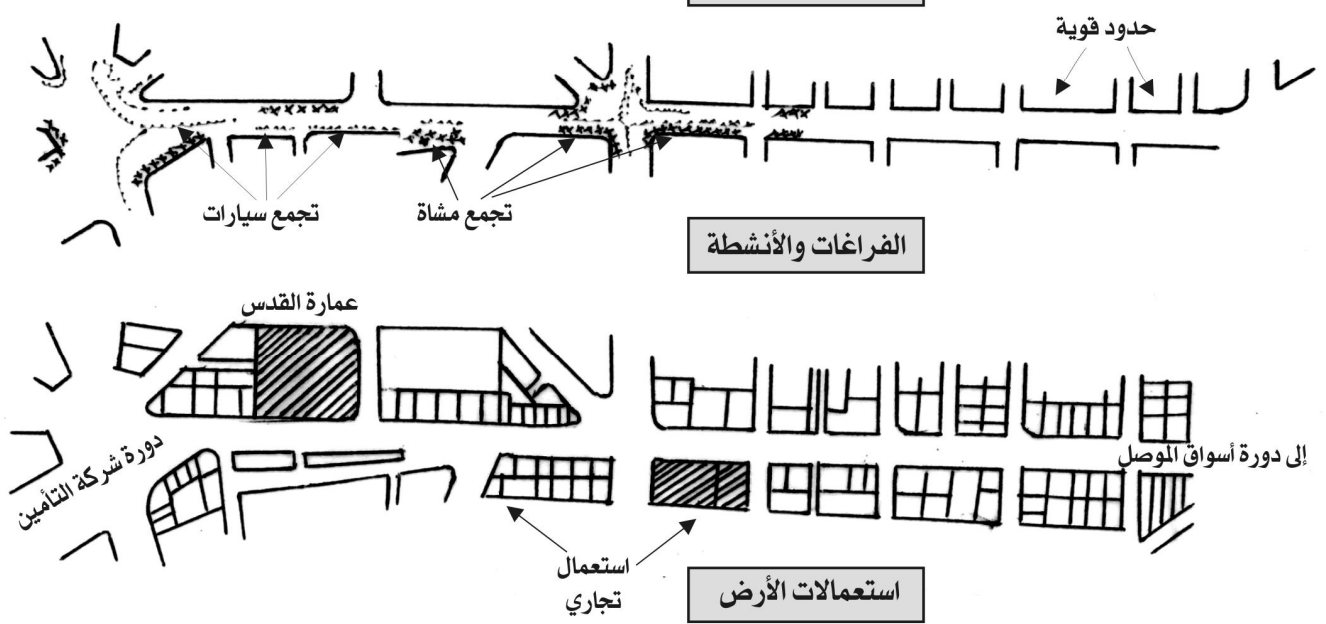

شكل (2) التحليل البصري لشارع الدواسة 


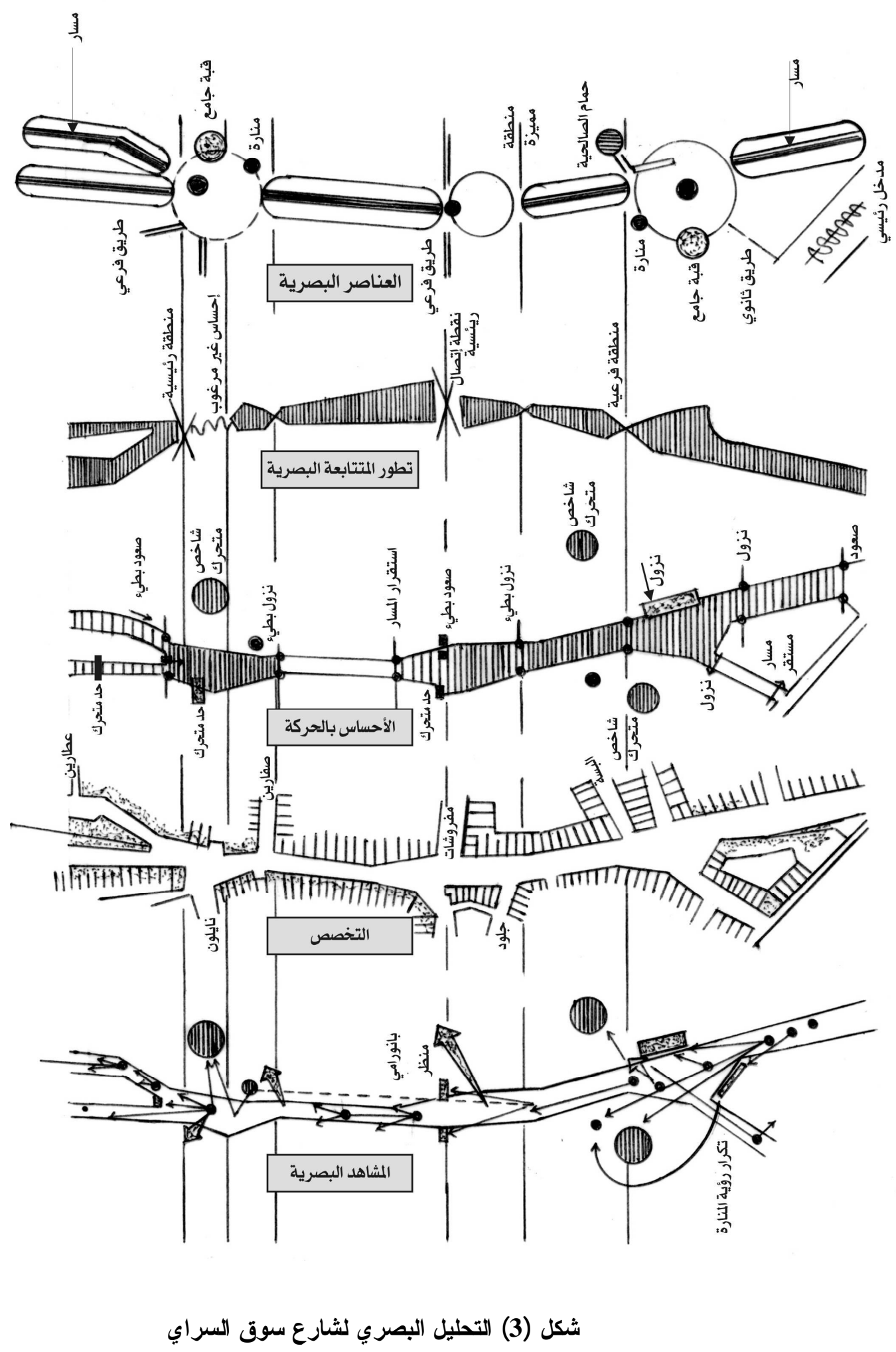



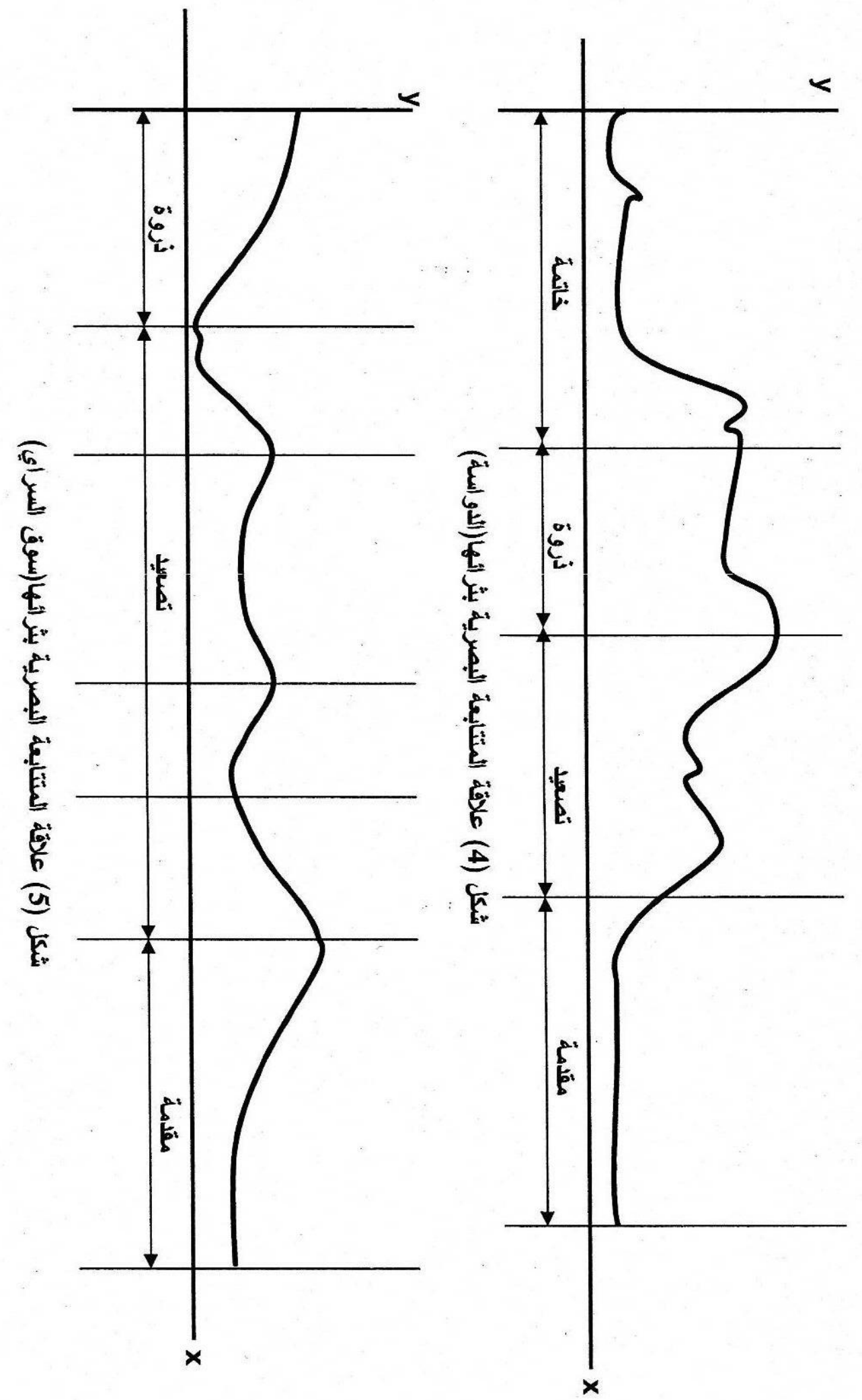

121 


\begin{tabular}{|c|c|c|c|}
\hline & \multicolumn{2}{|c|}{ جدول رقم (2) } & \\
\hline & المخارج & (1) الأحادية في المداخل & \\
\hline & \multicolumn{2}{|c|}{$\% 100:(\% 17) \% 50$} & \\
\hline \multicolumn{2}{|c|}{ التفردية في مداخل ومخار ج المسار } & \multicolumn{2}{|c|}{ التفردية حسب الاستعمال } \\
\hline (1) وجود الدخرج (2) & (1) وجود الدذخل (2) & (1) نوع الاستعمال (2) & (1) تتو ع الاستعمال \\
\hline$\checkmark$ & $\checkmark$ & تجاري & اكثر من نوع و احد : نوع واحد \\
\hline
\end{tabular}

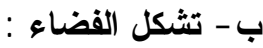

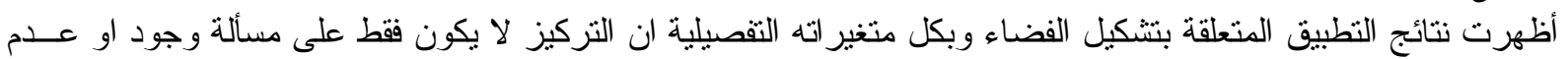

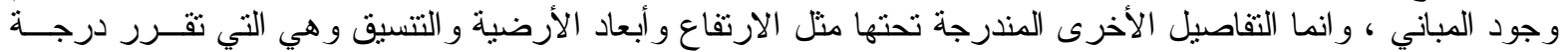

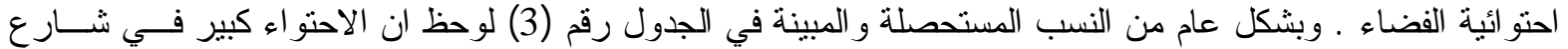

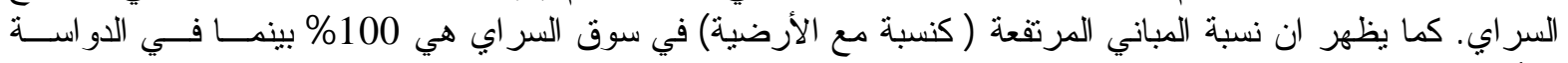

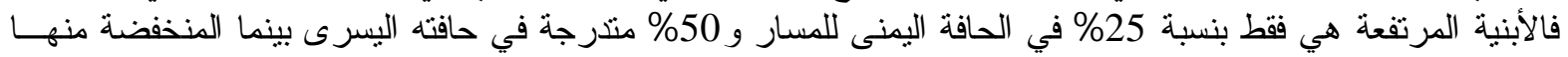

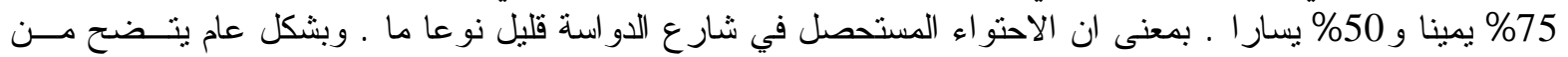

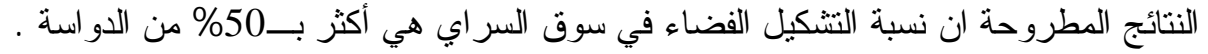

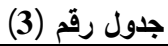

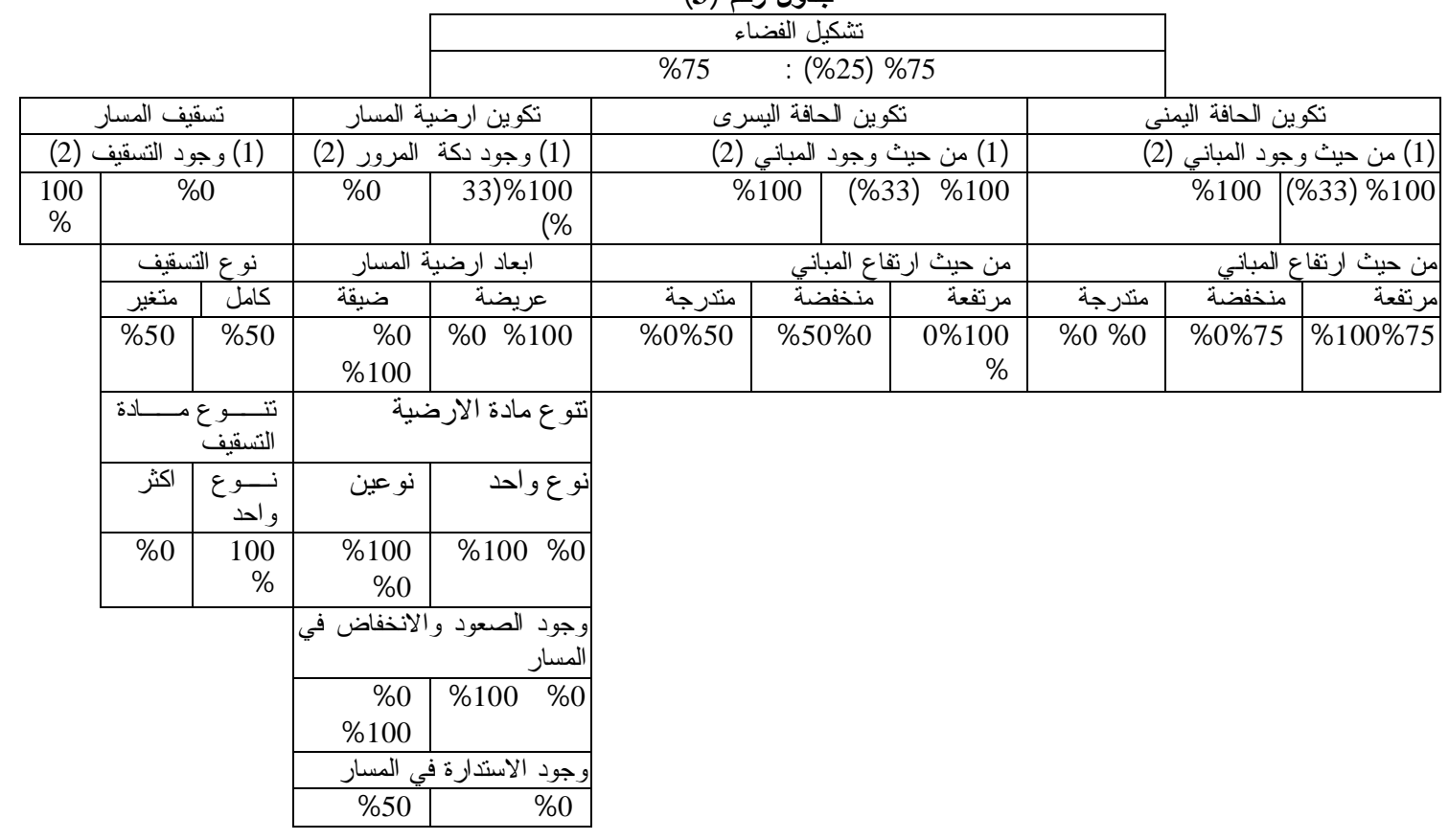

- الاستمر ارية بالنسب لتشكيل الفضاء :

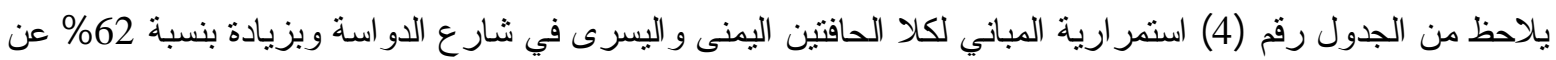

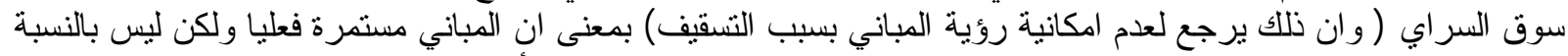

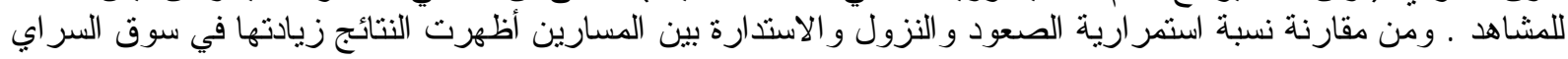

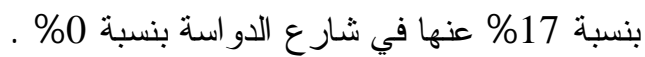

وعموما من مقارنة نسبة استمر ارية التشكيل الفضاء بشكل عام ولكل الفية المتغير ات المكونة له نلاحظ ان نسبة الاستمر ارية

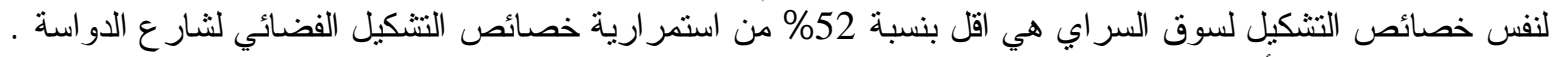
ان هذا يبين بوضوح أهمية التتوع الذي يخلق الحيوية في المسار بمعنى اخر ان استمر ارية خصائص التشكيل الفضائي 
لمسار ما تخلق نو عا من الملل وان عدم الاستمر ارية في هذه الخصائص و التي أظهر ها مسار شارع السراب يعزز من

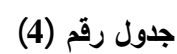

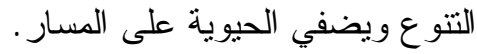

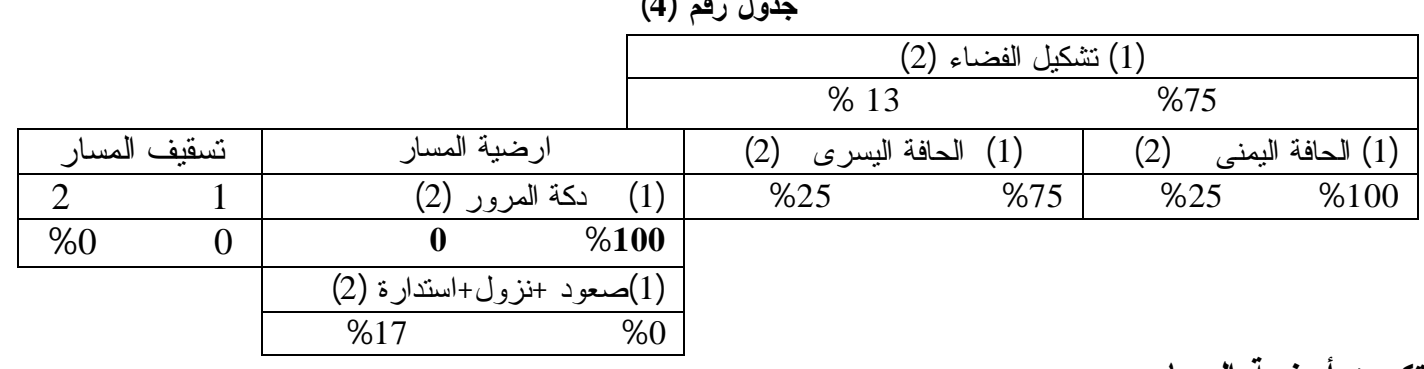

\section{جـ - جكوين أرضية المسار:}

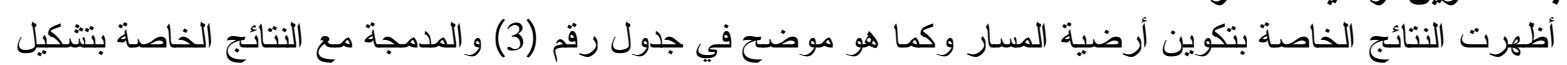

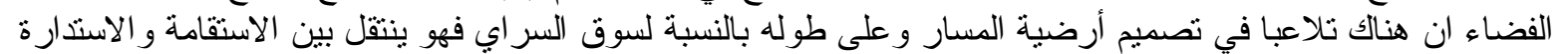

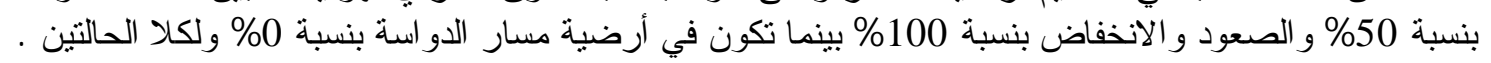

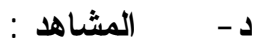

يبين الجدول رقم (5) الاختلاف بين المسارين قبد الدراسة في درجة تغيير المنظر حيث بلاحظ في سوق السراي ان نسبة

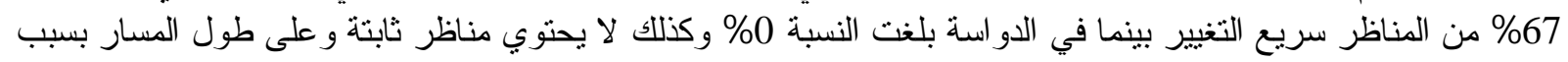

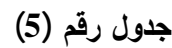

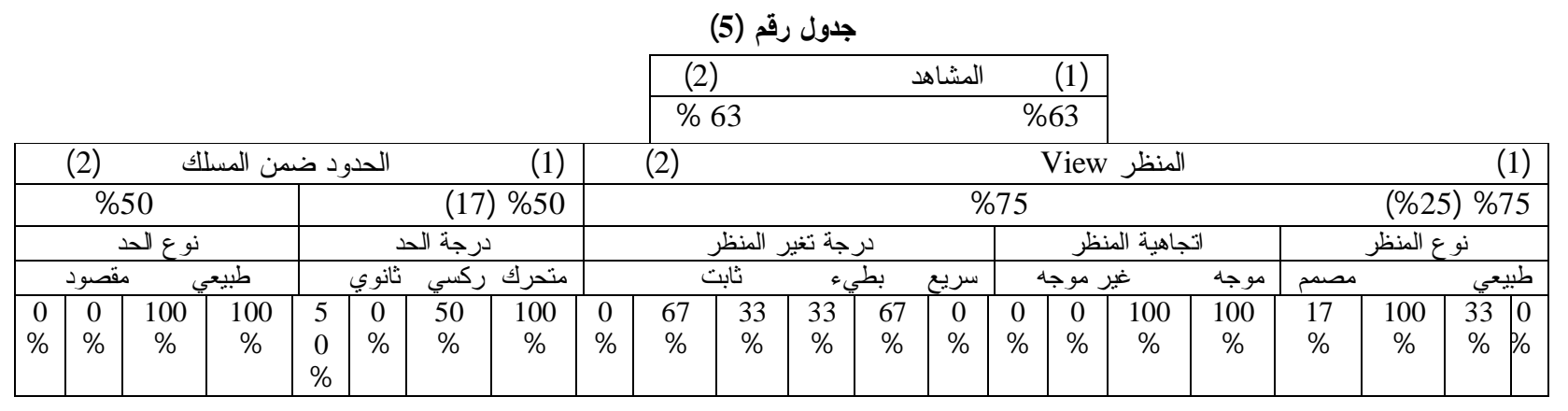

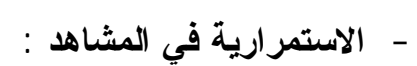

أظهرت نتائج التطبيق وكما موضح في الجدول (6) ان الاستمر ارية للمشاهدين في مسار الدواسة أكثر من استمر اريتها

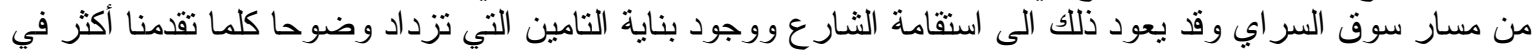

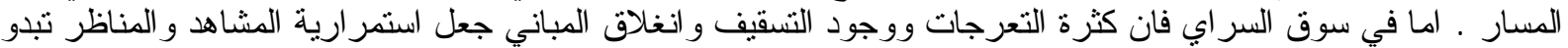

جدول رقم (6)

\begin{tabular}{|ccr|}
\hline$(2)$ & 1 (المشاهد| & $(1)$ \\
\hline$\% 33$ & & $(1)$ \\
\hline$(2)$ & \%40 \\
\hline$\% 33$ & & \\
\hline
\end{tabular}




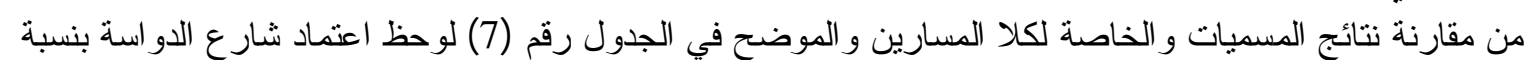

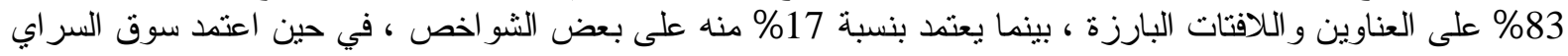

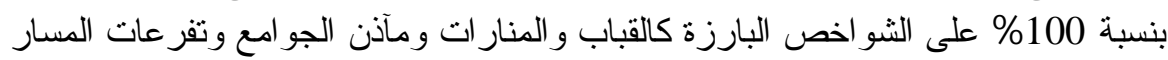

\section{جدول رقم (7) (7)}

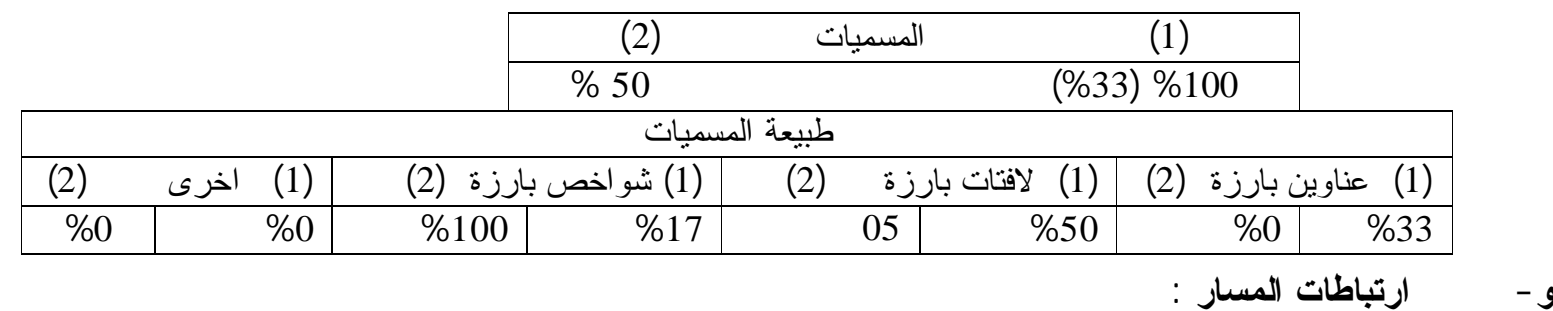

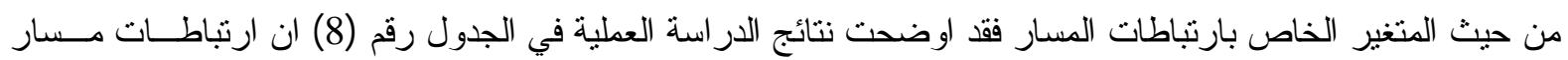

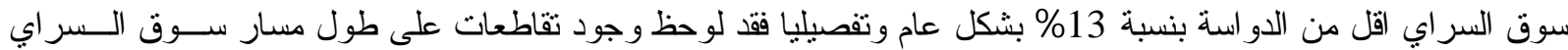

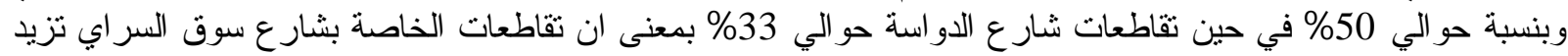

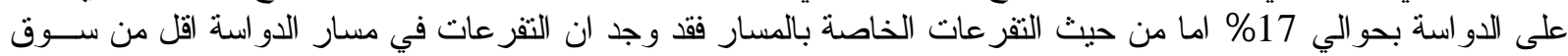

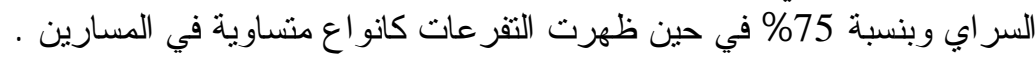

جدول رقم (8) (8)

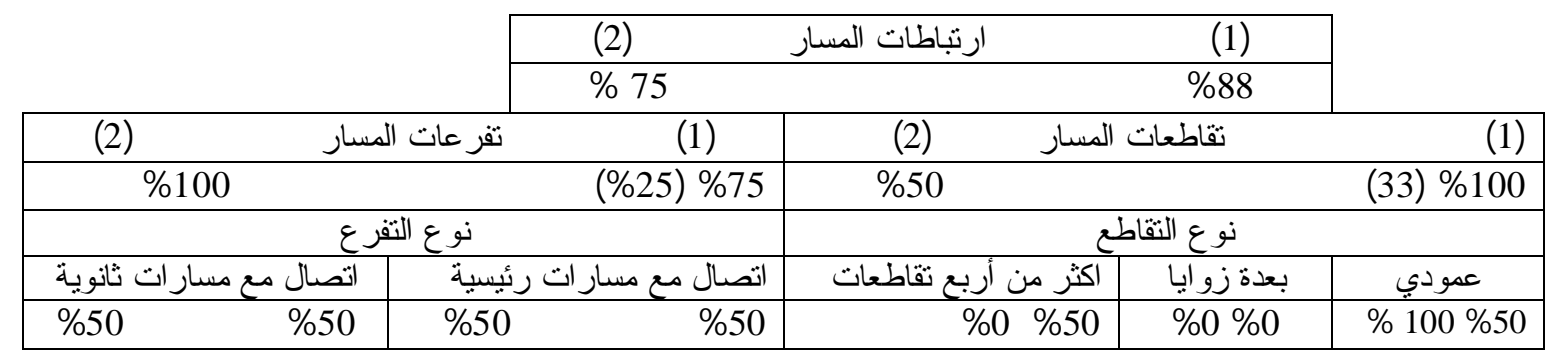

2-8

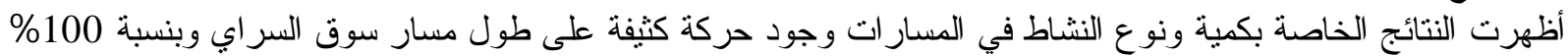

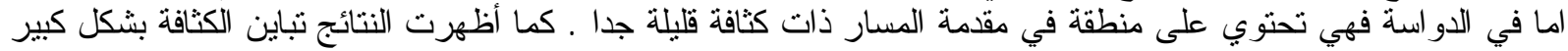

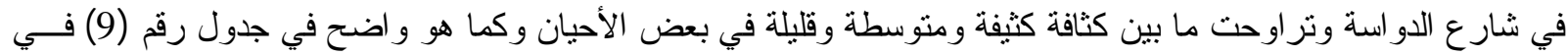

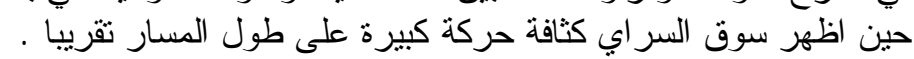

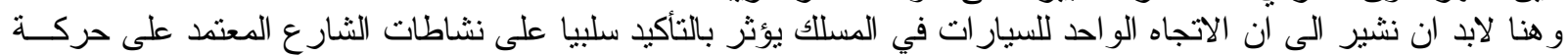

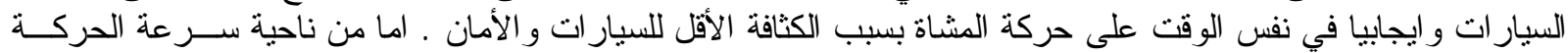

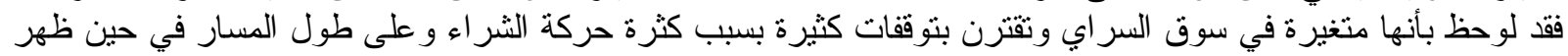

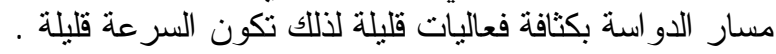

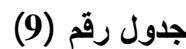

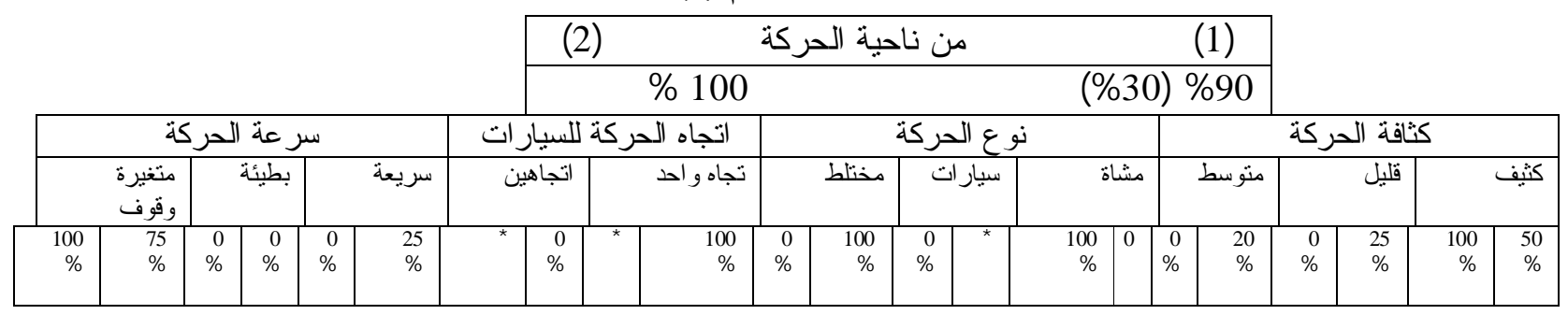




\section{-}

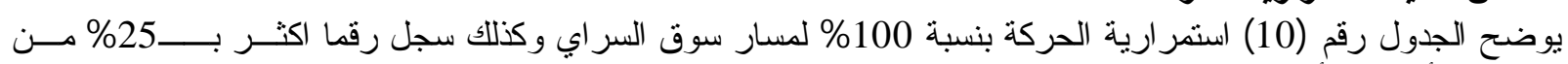
الدو اسة للأسباب الأنفة الذكر في الفقرة السابقة .

\begin{tabular}{|c|c|c|}
\hline \multicolumn{3}{|c|}{ (10 } \\
\hline (2) & استمر ارية الحركة & (1) \\
\hline$\% 100$ & & $\% 75$ \\
\hline
\end{tabular}

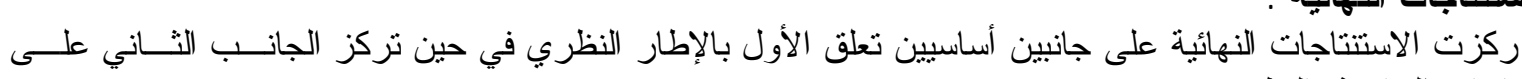
الاستتناجات الخاصة بالتطبيق.

: 1-9

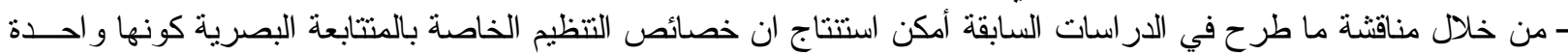

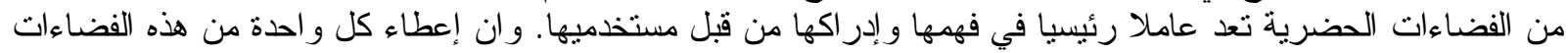

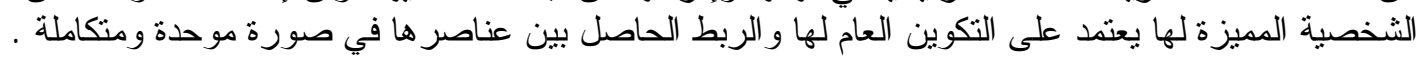

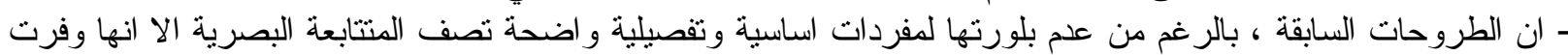

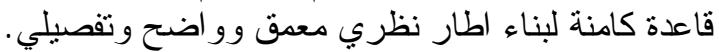

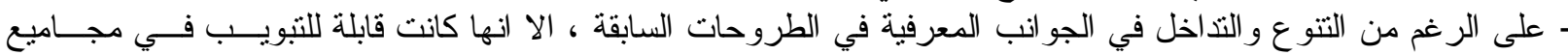

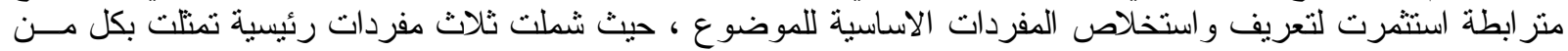

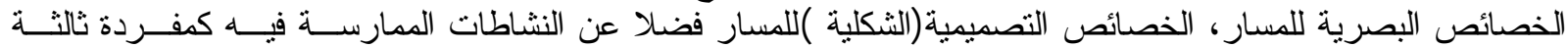

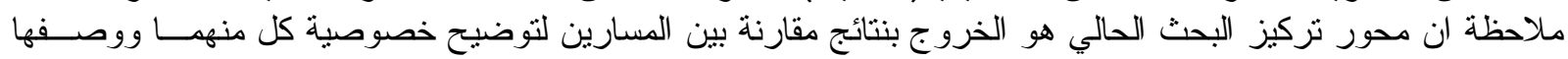

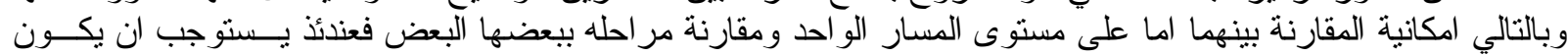

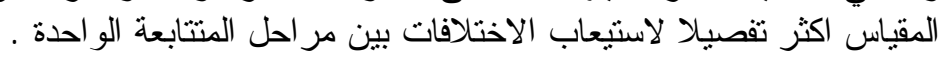

: 9

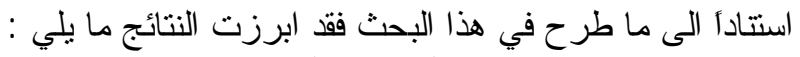

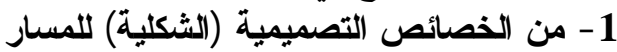

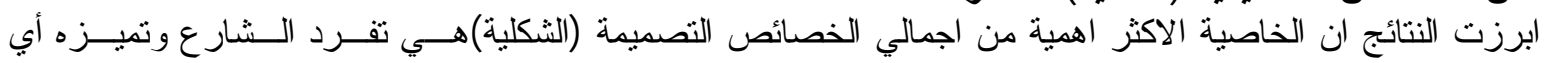
(الاحادية) ثم تلتها في الاهمية تتكيل الفضاء، ودرجة الاحتو اء، وارتباطات المسار واخير آلآ المشاهد البصرية.

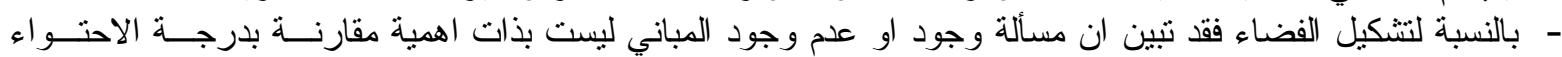

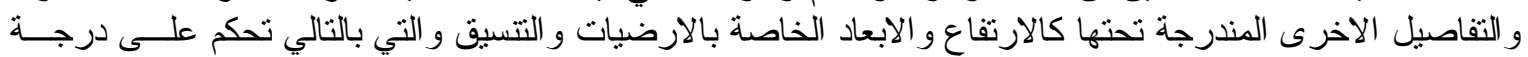

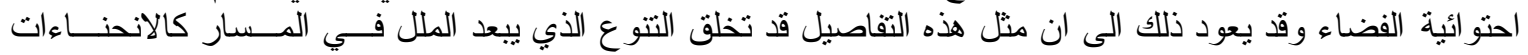

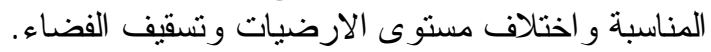

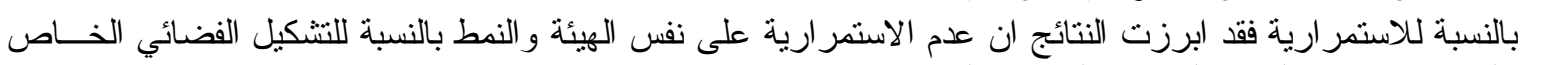

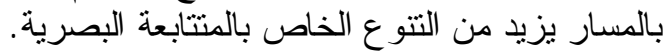

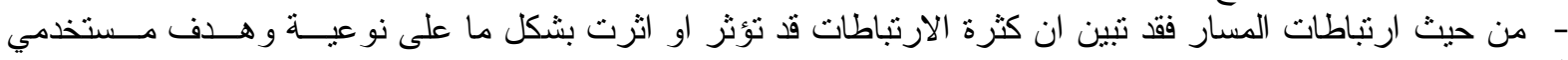
المسار.

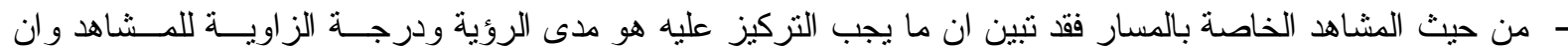

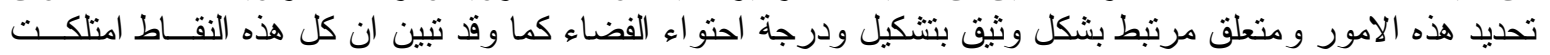

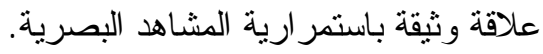

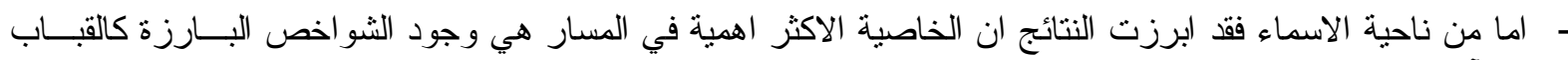

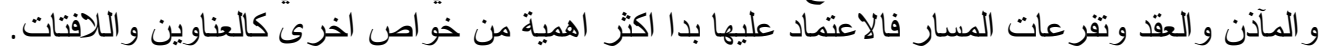

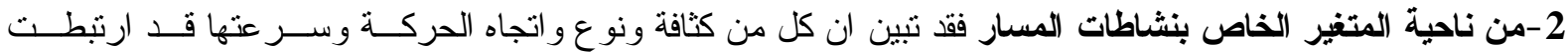
كعلاقة لنقطة مهمة و هي درجة انسيابية الحركة و استمر اريتها. 


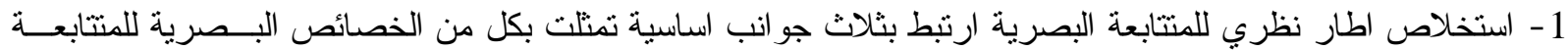

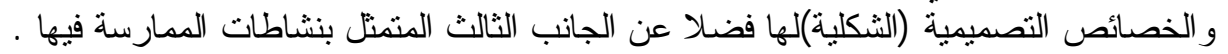

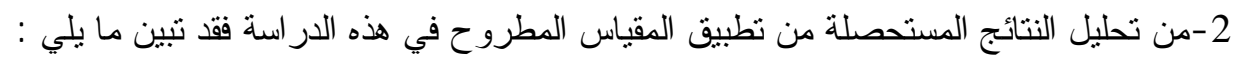

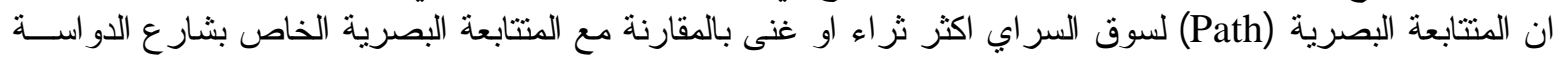

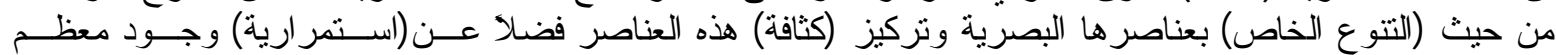

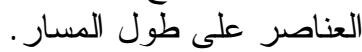

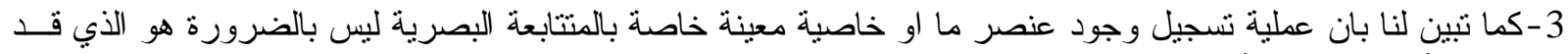

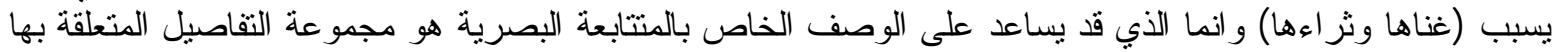

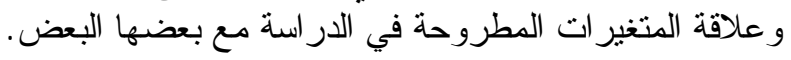

\footnotetext{
المصادر العربية والأجنبية

1 - جامعة بيروت العربية "التجمعات السكنية للمصانع" مشروع التجمع الصناعي للعاملين بشركة النــصر للكيمياويـات

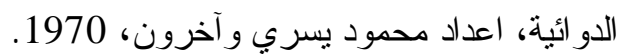

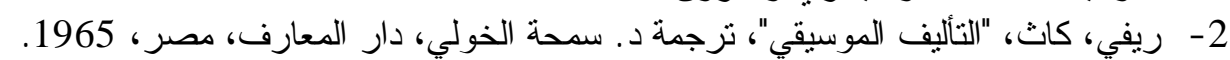

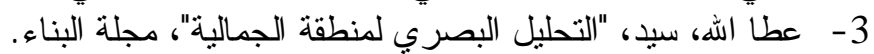

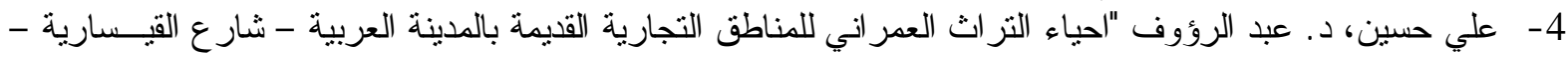
بمدينة اسيوط"، العمارة و البيئة، المجلد 2، الجز ء 3. 3، بغداد، 1989.

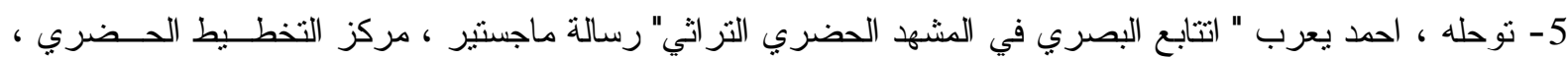
جامعة بغداد ، 1999 ( 199
}

6- Cullen, G, "The Cocise Townscape" the Architecture Press, London, 1974.

7- Lynch Kevin "The Image of the City " Cambridge, Massachusetts , 1961.

8- Lynch Kevin "The Image of the City" The MIT. Press, USA,1974.

9- Mc Cluskey, Jem " Road Form and Townscape " The Architectural Press, London , 1979.

10- Rappaort, Amos; " Human Aspects of Urban Form ", Pergomon Press, Oxford, 1977.

11- Papageorgio, E, "Continuity and Change;" Mackmillan, USA,1971.

تم اجراء البحث في كلية الهنسة - جامعة الموصل 